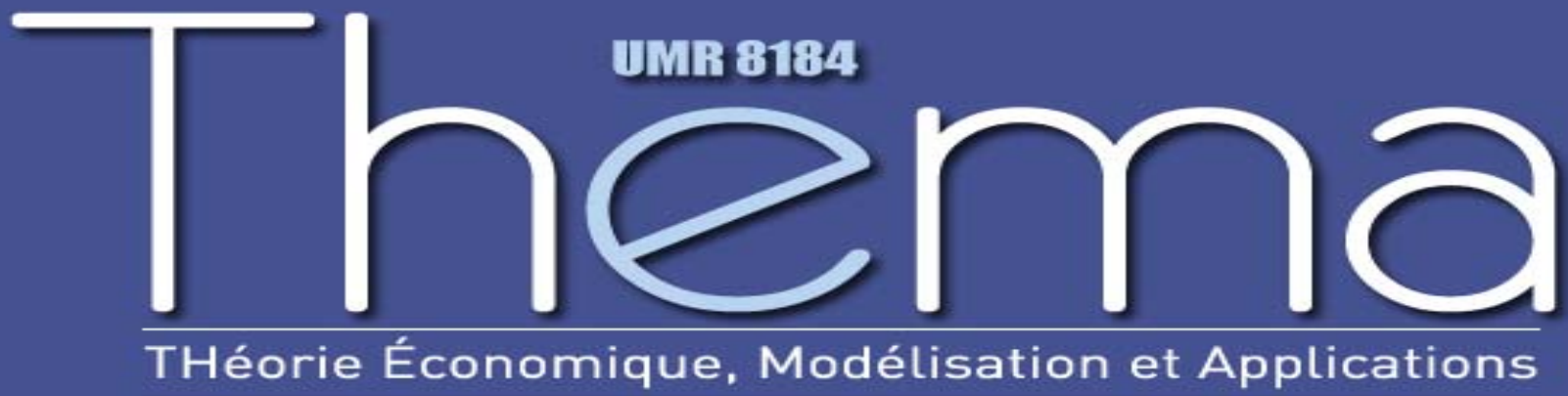

Thema Working Paper $n^{\circ} 2008-26$

University of Cergy Pontoise, France

\title{
Employment Protection Reform in Search
} Economies

O. L'Haridon

F. Malherbet

April 2008 


\title{
Employment Protection Reform in Search Economies
}

\author{
Olivier L'Haridon*and Franck Malherbet ${ }^{\ddagger}$
}

April 2008

\begin{abstract}
The design of employment protection legislation (EPL) is of particular importance in the European debate on the contours of labor market reform. In this article we appeal to an equilibrium unemployment model to investigate the virtues of EPL reform which reduces the red tape and legal costs associated with layoffs and introduces a U.S.-style experiencerating system, which we model as a combination of a layoff tax and a payroll subsidy. The reform considered shows that it is possible to improve the efficiency of employment protection policies without affecting the extent of worker protection on the labor market. These results are consistent with the conventional wisdom that experience rating is desirable, not only as an integral component of unemployment-compensation finance, as most studies acknowledge, but also as part and parcel of a virtuous EPL system.
\end{abstract}

JEL Code: J41 - J48 - J60

Keywords: Search and Matching Models, Employment Protection, State-Contingent Layoff Tax, Experience-Rating

\footnotetext{
${ }^{*}$ GREG-HEC and University Paris Sorbonne;

${ }^{\dagger}$ Corresponding author. THEMA - CNRS - Université de Cergy-Pontoise, IZA and fRDB; Address: Université de Cergy-Pontoise, THEMA, 33 Boulevard du port, 95011 Cergy-Pontoise cedex, France; Email: franck.malherbet@u-cergy.fr.

${ }^{\ddagger}$ We are indebted to Tito Boeri, Pierre Cahuc, Olivier Charlot, Bruno Decreuse, Pietro Garibaldi, Jean-Olivier Hairault, Michael Kiley, Francis Kramarz, Jocelyn Martel, Christopher Pissarides, Fabien Postel-Vinay, André Zylberberg and two anonymous referee and an associate editor for valuable comments and suggestions. We are also grateful to seminar participants at EUREQua-Université Paris I, the Institute for the Study of Labor (IZA), the CEPR DAEUP meetings, the T2M conference, the EEA and ESEM conferences, the EALE conference and the ERC/METU conference. This paper has benefited from the support of the CEPR DAEUP network. All errors remain our sole responsibility.
} 


\section{Introduction}

Over the past few decades, most continental European countries have experienced high and persistent unemployment rates, while the U.S. labor market has performed relatively well. The bulk of labor market research has tackled these contrasting situations by emphasizing the effect of employment protection legislation, hereafter EPL, on labor market performance. As a result, the importance of labor market flexibility has been widely acknowledged. This view can be summarized by the expressed desire of the E.U. council to give member States incentives to "review and, where appropriate, reform overly restrictive elements in employment legislation that affect labor market dynamics [...] and to undertake other appropriate measures to promote a better balance between work and private life and between flexibility and security". It is however striking that most of the reforms undertaken in the last two decades have contrasted sharply with this latter recommendation of favoring reforms at the margin in continental Europe. More precisely, reforms have fostered two-tier systems, as the increase in labor market flexibility has taken place mainly through a series of marginal reforms that liberalized the use of fixedterm and/or non-standard employment contracts, favoring the status quo for workers employed on conventional contracts (OECD, 2004 and 2005). It follows that employment protection arises in a very particular form in such two-tier labor markets because there are both highlyprotected stable jobs and unstable jobs with short durations and little protection. The marginal reforms produce a divided labor market, with an unequal repartition of risk between workers and uncertain effects on economic outcomes (Blanchard and Landier, 2002, Cahuc and Postel-Vinay, 2002, and Boeri and Garibaldi, 2007). In addition a number of authors have pointed out that workers with regular contracts may only be superficially protected, as indicated by the very few fair or justified dismissals in job destruction flows (Boeri, Bertola and Cazes, 2002, and Cahuc and Kramarz, 2005).

Designing Employment Protection Reform: Given the limitations of current EPL, it seems legitimate to ask what a good reform of employment protection would look like. This seemingly simple question is hotly debated in the context of European employment protection reforms (E.U. Council, 2003, and OECD, 2004). In the particular case of France, a series of recent policy reports has tried to outline the design of such reforms (Blanchard and Tirole, 2003a, Cahuc, 2003, and Cahuc et al., 2005). In the words of Blanchard and Tirole (2003b) such a reform should:

"[...] increase the contribution rate of firms (that is to introduce a layoff tax, and decrease the corresponding payroll tax) so firms internalize the cost of unemployment. 
[...] limit the role of the judicial system. To the extent that firms are willing to incur the financial costs associated with laying off workers [...] judges should not be allowed to second guess the firms' decision."

With respect to European institutions, it is obvious that these two recommendations are at odds with most current European systems, and in particular with the French labor market where firms' marginal contribution rate is zero and where layoffs are subject to heavy administrative and legal constraints. These recommendations reflect the U.S. unemployment insurance system: while layoff costs are mostly due to EPL in European countries, they essentially come from experience-rated unemployment insurance in the U.S.. The systematic use of experience rating is a particular feature of U.S. unemployment benefits, where in most states firms are taxed as a function of their separations. As such, experience rating is a way of requiring employers to contribute to the benefit payments they cause via their firing decisions. This internalizes the cost of an additional layoff to the unemployment insurance system for firms. To our knowledge, experience rating is unique to the U.S. (Baicker, Goldin and Katz, 1997) and is absent from all other OECD countries (see Holmlund, 1998, for a survey).

In this article, we evaluate the effects of an EPL reform which would introduce a U.S.-like experience-rating system, modeled as a combination of both a layoff tax and a payroll subsidy, and a reduction in the red tape and legal costs associated with layoffs. It is worth noting that whereas the debate on employment protection reform has mainly asked whether it is desirable to tighten the stringency of EPL, the approach advocated here takes a different perspective. We rather consider whether it is possible to improve the efficiency of EPL for a constant degree of stringency, i.e. to reform employment protection while leaving workers' job security unchanged.

What can we expect from the introduction of such a layoff tax? Since Feldstein's (1976) seminal paper, an abundant literature has developed dealing with the effects of experience rating. ${ }^{1}$ Feldstein (1976) was among the first to offer a theoretical analysis of experience rating in a model of temporary layoffs, which are frequent in the U.S. economy. The arguments in favor of experience rating stem from the fact that the payroll taxes used to finance unemployment benefits give rise to inefficiently high levels of layoffs, as firms do not take into account the cost of financing the benefits paid to unemployed workers. To avoid this excess job destruction, unemployment benefits should be financed through a layoff tax. A system with perfect experience rating will likely reduce temporary layoffs and improve labor market performance. This view has been challenged ${ }^{2}$ by Burdett and Wright (1989), Marceau (1993) and more recently by Mongrain

\footnotetext{
${ }^{1}$ See Holmlund (1998) or Malherbet (2003) for a survey.

${ }^{2}$ See Malherbet (2003) or Cahuc and Malherbet (2004) for a discussion.
} 
and Roberts (2005) who show that a perfect experience-rating system may produce adverse labor market outcomes. In general, the empirical analysis of experience rating supports the analysis proposed by Feldstein (1976), finding strong evidence that experience rating decreases unemployment (Anderson, 1993, Card and Levine, 1994 and Anderson and Meyer, 2000).

It may be tempting to generalize the results of the main U.S. studies in this area to Europe. However, the U.S. results need to be interpreted cautiously in the European context for at least two reasons: (i) The U.S. labor market is unusual in that it is often considered as being particularly flexible - In the European case, complementarities between various public policies, and especially those related to EPL, may well modify the U.S. results (Blanchard et al., 2003a, and L'Haridon, 2005); (ii) Temporary layoffs are much less common in Europe and other OECD countries than in the U.S. (OECD, 2002).

To address all of these issues, we consider an economic framework allowing for worker mobility between firms. Equilibrium unemployment models are, from this standpoint, good candidates to shed light on the effects of EPL reform. Indeed this class of models has proven to be relevant in taking account of the effects of both EPL and permanent layoffs on labor-market dynamics. ${ }^{3}$

Related Literature: The contributions most closely related to the current paper are Fath and Fuest (2005), Mongrain et al. (2005) and Cahuc et al. (2004) all of which deal with the question of experience rating in the presence of miscellaneous labor-market institutions. Fath et al. (2005) liken severance payments to experience rating in a dynamic efficiency-wage model with endogenous worker monitoring and endogenous layoffs. They find that the introduction of an experience-rated tax increases employment and welfare in this framework. The mechanism is simple. An increase in the the degree of experience rating or severance payments lowers monitoring intensity, as this activity is costly for the firm. However, in contrast to severance payments, experience rating reduces the payroll tax and does not affect worker effort since the layoff tax is not a transfer from the firm to the worker. In a fairly similar setting, Mongrain and Roberts (2005) show, in a static model where firms offer private insurance, that with a high degree of experience rating firms may reduce their severance payments by more than the level of unemployment benefits, producing a welfare loss for workers. Cahuc and Malherbet (2004) appeal to a search and matching model to highlight the effects of the introduction of an experience-rated tax in a prototypical European continental labor market with two-tier contracts (short-term and long-term) as well as other pervasive institutions. They consider a particular segment of the labor market where unskilled workers are paid the minimum wage. In this context

\footnotetext{
${ }^{3}$ See, among others, Millard and Mortensen (1997) and Albrecht and Vroman (1999).
} 
they find that the combination of minimum wage, temporary contracts and stringent EPL can give rise to a form of labor market regulation where experience rating is desirable.

This article is along the lines of the work discussed above. Our analysis stands out from the efficiency-wage model proposed by Fath et al. (2005) and Mongrain et al. (2005) by considering a more general framework with search frictions and by integrating another important EPL component, i.e. the red tape and legal costs associated with layoffs whose predominance over severance payments is widely acknowledged in most European countries (See Blanchard, 2000, and Kramarz and Michaud, 2004, in the particular case of France.). In addition, our work generalizes the contribution of Cahuc and Malherbet (2004) to a more elaborate framework where the whole population is considered, wages are freely bargained, and the economy is subject to macroeconomic shocks. This latter component is introduced insofar as the effects of statecontingent layoff taxes are likely to be more harmful to firms when aggregate conditions are depressed. In addition, our analysis sheds light on the dynamic effect of EPL reform, in contrast to with previous contributions whose focus was rather on the steady-state.

We specifically provide a search and matching model in the style of Mortensen and Pissarides (1994) with the following key ingredients: (i) match-specific heterogeneity meant to reflect the quality of the firm-worker relationship; (ii) an aggregate productivity element which captures changes in the macroeconomic environment; (iii) a series of restrictive EPL mechanisms reflecting the stringency of employment protection, capturing both the layoff tax and red tape and legal costs; and (iv) a general wage-setting mechanism which captures the effects of both EPL components on salaries.

The theoretical analysis leads us to argue that a state-contingent layoff tax differs significantly from the conventional EPL package. The calibration of our model confirms that EPL reform will improve overall labor-market performance, thereby alleviating the unemployment-insurance budget, increasing production and reducing the aggregate unemployment rate. This latter effect is stronger the worse are aggregate macroeconomic conditions. In addition, time-series analysis provides strong empirical evidence that state-contingent layoff taxes stabilize labor-market flows and employment over the business cycle. The broad conclusion from our analysis is that EPL reform can give rise to a form of labor-market regulation where the efficiency of employment protection is improved, while leaving overall worker security in the labor market unaffected.

The outline of this article is as follows. Section 2 presents the conceptual framework used to analyze the effects of EPL reform. Section 3 discusses the labor-market general-equilibrium perspective and presents a variety of simulations to assess the effects of the reform. Section 4 
concludes.

\section{The Model}

This section outlines the economic environment in which we analyze the employment effects of EPL reform. The model builds on and extends the continuous-time search and matching framework developed and surveyed by Mortensen and Pissarides (1999a,b) and Pissarides (2000).

\subsection{Preliminary Assumptions}

The assumptions are essentially common to the search and matching literature ${ }^{4}$ and are therefore only briefly sketched unless necessary.

Demography and Preferences: Time is continuous. There are two goods in the economy: labor, which is the sole input, and a numeraire good which is produced and consumed. The labor market is populated by a measure one of infinitely-lived workers. Each worker supplies one unit of labor and can be either employed and producing or unemployed and searching. All agents discount future payoffs at the rate $\rho>0$, and are risk neutral. The choice of a linear utility function is a standard assumption in the search literature and is used in order to keep the environment as simple as possible. ${ }^{5}$ This assumption implies that we restrict our analysis to the employment consequences of EPL reform and thereby skirt any insurance issues which, although important, are beyond the scope of this paper. ${ }^{6}$

Macroeconomic Environment and Production: Unlike the standard search and matching framework, the model here allows for turbulence at the macroeconomic level. We assume that the aggregate economic environment moves stochastically between $n$ states according to an arbitrary Markov process with persistence. A transition matrix, $\Omega$, whose elements are the instantaneous transition probabilities from one state to another, is associated with this process. Aggregate states are indexed by subscript $i \in[1, n]$ and are ranked in descending order with $i=1$ standing for the best aggregate state.

There is a continuum of small firms, the number of which is endogenous in equilibrium. Firms have a single job slot and either produce with one worker, or search with an open vacancy. For a given aggregate state $i$, each job is endowed with an irreversible production technology requiring one unit of labor to produce $p_{i}+\sigma \varepsilon$ units of output, where $\sigma$ is an indicator of the

\footnotetext{
${ }^{4}$ See Rogerson, Shimer and Wright (2005) for an exhaustive survey.

${ }^{5}$ Introducing a non-linear utility function into a search and matching model with endogenous job destruction and bargained wages adds a degree of complexity that we would rather avoid here.

${ }^{6}$ See, among others, Bertola (2004), Blanchard and Tirole (2008) and Pissarides (2001) for a discussion of the insurance role of employment protection.
} 
dispersion in the idiosyncratic component. Productivity is made up of two components: (i) an aggregate component, $p_{i}$, which is contingent to the state of nature and common to all jobs; and (ii) an idiosyncratic component, $\sigma \varepsilon$, which is match-specific. Total productivity is therefore subject to two sources of uncertainty: (i) a microeconomic or idiosyncratic source; and (ii) a macroeconomic or aggregate source. The product of a match changes from time to time without warning. The stochastic process governing the idiosyncratic component of productivity $\varepsilon$ is Poisson with arrival rate $\lambda$. In the event of such a shock, a new value of job-specific productivity is drawn from a cumulative distribution function $G(\varepsilon)$ with support over the range $\left[\varepsilon_{l}, \varepsilon_{u}\right]$. Given an aggregate state $i$, the existing filled jobs are destroyed only if the new value of $\varepsilon$ falls below an endogenous and state-contingent threshold denoted by $\varepsilon_{d_{i}}$. As a consequence, the rate at which existing jobs are destroyed follows a Poisson process with parameter $\lambda G\left(\varepsilon_{d_{i}}\right)$. The aggregate component of productivity $p_{i}$ changes according to the Markov process described above. It is worth noting that although aggregate shocks do not affect job-specific productivity, they do induce changes in the state-contingent threshold, $\varepsilon_{d_{i}}$. As a consequence, aggregate turbulence may lead to the termination of some jobs. The mechanism is described in depth in the core of the paper. ${ }^{7}$

Matching: Vacant jobs and unemployed workers are brought together in pairs via an imperfect matching process. In each state $i$, this process is captured by an aggregate matching function $M\left(v_{i}, u_{i}\right)$, where $v_{i}$ and $u_{i}$ designate the vacancy and unemployment rates respectively. With this formulation, only unemployed persons are assumed to be job applicants. In other words, it comes down to neglecting on the job search activities. The function $M\left(v_{i}, u_{i}\right)$ is assumed to be strictly increasing with respect to each of its arguments and to exhibit constant returns to scale. The linear homogeneity of the matching function allows us to write the transition rate for vacancies as $M\left(v_{i}, u_{i}\right) / v_{i}=M\left(1, u_{i} / v_{i}\right)=q\left(\theta_{i}\right)$, where $\theta_{i}=v_{i} / u_{i}$ stands for labor-market tightness in aggregate state $i$. Similarly, the flow out of unemployment is given by $M\left(v_{i}, u_{i}\right) / u_{i}=\theta_{i} q\left(\theta_{i}\right)$. The properties of the matching function imply that $q\left(\theta_{i}\right)$ and $\theta_{i} q\left(\theta_{i}\right)$ are respectively decreasing and increasing in labor market tightness. Upon matching, a common start-up productivity level ${ }^{8}$, $\varepsilon_{u}$, is assumed for all job-worker matches. It follows that all vacancies in a given aggregate state are identical ex ante and have an associated productivity level of $p_{i}+\sigma \varepsilon_{u}$.

Employment Protection Legislation (EPL): Any employment relation may be terminated

\footnotetext{
${ }^{7}$ See section 2.4 below for the mechanisms driving job destruction.

${ }^{8}$ This assumption is used for simplicity's sake. Under a stochastic job-matching hypothesis (see Pissarides, 2000 chapter 6 ) it can be shown that the properties of the model are unaffected. A Technical Appendix is available from the authors on request.
} 
once a cost, $f+\tau_{e_{i}}$, is paid by the firm. The first component of this cost, $f$, stands for a generic measure of employment protection and is assumed to capture the red tape and legal costs associated with layoffs. This assumption is justified on two grounds. First, in most European countries, and particularly in France, employment termination takes time and is extremely costly. Second, termination costs generally vastly exceed severance payments (Blanchard, 2000, and Kramarz and Michaud, 2004). The parameter $f$ therefore reflects a state-mandated cost rather than a transfer from the firm to the worker. ${ }^{9}$ The second cost component, $\tau_{e_{i}}$, is a layoff tax designed to finance the unemployment-compensation system. This tax has the three following characteristics ${ }^{10}$ : (i) it is a layoff tax and, as a consequence, affects the firm's layoff decisions; (ii) it is used to finance the unemployment benefits paid to unemployed workers and thereby constitutes a revenue source for the unemployment-compensation system; and (iii) it is contingent on the state of nature, since the system's funding is indexed on the average length of unemployment spells. Further details are provided below.

Wage Bargaining: The existence of transaction costs on the labor market gives rise to a local monopoly rent equal to the difference between what the individual obtains in the contractual job-worker relationship and their best opportunity outside the contract. The match surplus is divided between the firm and the worker according to a wage rule. Following the bulk of the search and matching literature, we assume that the surplus is split between the firm and the worker according to a generalized Nash criterion (see, for instance, Mortensen and Pissarides, 1999a, Pissarides, 2000 and Rogerson et al., 2005). In this framework, bargaining provides each participant with a share of the surplus which is proportional to her bargaining power, denoted by $\gamma \in[0 ; 1]$. We assume that wages are renegotiated each time new information regarding the job-worker match is revealed, which occurs at the Poisson rate $\lambda$. EPL modifies the shape of wage bargaining and implies a two-tier bargaining structure. ${ }^{11}$ In fact, EPL requires us to

\footnotetext{
${ }^{9}$ Our decision not to formalize severance payments is justified for two reasons. First, as already mentioned, severance payments are generally smaller than red tape and legal costs. Second, the classical "bonding critique" emphasized by Lazear (1990) stipulates that, in the absence of contractual frictions, severance payments can be canceled out by an appropriate wage contract. Then for the reasons pointed out in Lazear (1990), the equilibrium values of the key decision variables remain unaffected by severance payments. Since the framework used here is exempt of contractual frictions this assumption is not restrictive. For more details on the effects of contractual frictions in search and matching models, see Garibaldi and Violante (2005).

${ }^{10}$ The rationale behind the state-contingent layoff tax, $\tau_{e_{i}}$, borrows from the experience-rating schemes implemented in the United States. In particular, in the U.S. the experience-rated tax is paid over time rather than at the time of layoffs or when unemployment benefits are paid out to workers. Such considerations entail a degree of complexity which we would rather avoid here. Hence, for simplicity's sake, we assume an experience-rating schedule that has no memory and call it a state-contingent layoff tax. As far as we know, all of the papers devoted to experience rating have adopted this assumption. The analysis of the dynamic consequences of an experience-rated system with memory would be an extremely interesting extension to consider in future research.

${ }^{11}$ Some authors have questioned the plausibility of this two-tier bargaining structure (Lindbeck and Snower, 1988, and McLeod and Malcomson, 1993). Indeed, in the absence of a two-tier agreement, hold-up problems may arise, and in such cases job creation outcomes are generally different. It may be demonstrated that alternative
} 
distinguish between wage negotiation upon first meeting and wage renegotiation. EPL applies and is binding in the latter case but not in the former, since no contract has yet been signed. As noted by Mortensen and Pissarides (1999a), this dual structure is similar to the insider-outsider conflict described by Lindbeck and Snower (1988) where the outsiders (the unemployed workers) do not profit from EPL whereas the insiders (the employed workers) use it to strengthen their negotiating position.

\subsection{Values}

A job can be in one of the three following states: vacant, recently filled or continuing. Each of these states has a corresponding asset value $\Pi_{v_{i}}$ for a firm with a vacancy, $\Pi_{o_{i}}$ for a firm matched with an outsider, and $\Pi_{e_{i}}$ for a firm matched with an insider. A vacant job costs $h$ per unit of time. Let $q\left(\theta_{i}\right)$ and $\Omega_{i j}$ denote the respective transition rates for filling a vacancy and for switching from aggregate state $i$ to state $j$. The asset value of a vacancy in state $i$ is such that:

$$
\rho \Pi_{v_{i}}=-h+q\left(\theta_{i}\right)\left[\Pi_{o_{i}}\left(\varepsilon_{u}\right)-\Pi_{v_{i}}\right]+\sum_{i \neq j}^{n} \Omega_{i j}\left[\Pi_{v_{j}}-\Pi_{v_{i}}\right], \forall i, j=1 \ldots n,
$$

where $\Pi_{o_{i}}\left(\varepsilon_{u}\right)$ is the expected value of a new job at the upper bound of the productivity distribution. This equation simply states that the firm pays a flow cost, $h$, realizes a capital gain, $\left[\Pi_{o_{i}}\left(\varepsilon_{u}\right)-\Pi_{v_{i}}\right]$, at the time of recruitment, and takes account of the possible changes at Poisson rate $\Omega_{i j}$ in aggregate conditions. EPL implies a two-tier agreement which requires us to distinguish between the asset value of newly-created and continuing jobs. The value of a new match to the employer in state $i$ is thus:

$$
\begin{aligned}
\rho \Pi_{o_{i}}\left(\varepsilon_{u}\right) & =p_{i}+\sigma \varepsilon_{u}-w_{o_{i}}\left(\varepsilon_{u}\right)-\tau_{i} \\
& +\lambda\left[\int \operatorname{Max}\left[\Pi_{e_{i}}(\zeta), \Pi_{v_{i}}-\tau_{e_{i}}-f\right] d G(\zeta)-\Pi_{o_{i}}\left(\varepsilon_{u}\right)\right] \\
& +\sum_{i \neq j}^{n} \Omega_{i j}\left[\Pi_{o_{j}}\left(\varepsilon_{u}\right)-\Pi_{o_{i}}\left(\varepsilon_{u}\right)\right], \forall i, j=1 \ldots n,
\end{aligned}
$$

where $w_{o_{i}}\left(\varepsilon_{u}\right)$ is the wage paid to outsiders and $\tau_{i}$ is a lump-sum payroll tax. The equity value of the firm in state $i$ is equal to the instantaneous flow profit, $p_{i}+\sigma \varepsilon_{u}-w_{o_{i}}\left(\varepsilon_{u}\right)-\tau_{i}$, plus the firm's anticipation of capital change due to either a specific or an aggregate shock. In the event of a specific shock, the firm retains the option of firing the worker if the new value of productivity is below the reservation threshold, $\varepsilon_{d_{i}}$. In this case the firm bears the dismissal costs of $\tau_{e_{i}}+f$.

wage specifications do not alter the results of our model. For instance under a pure insider model it can be shown that the qualitative results remain unchanged. We hence restrict ourselves to the main effect of the reform using the standard specification (see Mortensen and Pissarides, 1999a, for a discussion of rent sharing with turnover costs). 
Note that in the event of an aggregate shock which affects the equity value, the job is never destroyed since it remains at the upper bound, $\varepsilon_{u}$, of the productivity distribution. Finally, the value to the employer of continuing the match in state $i$ is:

$$
\begin{aligned}
\rho \Pi_{e_{i}}(\varepsilon) & =p_{i}+\sigma \varepsilon-w_{i}(\varepsilon)-\tau_{i} \\
& +\lambda\left[\int \operatorname{Max}\left[\Pi_{e_{i}}(\zeta), \Pi_{v_{i}}-\tau_{e_{i}}-f\right] d G(\zeta)-\Pi_{e_{i}}(\varepsilon)\right] \\
& +\sum_{i \neq j}^{n} \Omega_{i j}\left[\operatorname{Max}\left[\Pi_{e_{j}}(\varepsilon), \Pi_{v_{j}}-\tau_{e_{j}}-f\right]-\Pi_{e_{i}}(\varepsilon)\right], \forall i, j=1 \ldots n,
\end{aligned}
$$

where $w_{i}(\varepsilon)$ is the wage paid to insiders at productivity $\varepsilon$. Here however, unlike the case in equation (2), shifts in aggregate conditions may lead to job termination, producing the Max operator in the last term of (3). Although aggregate shocks do not affect the idiosyncratic component of productivity, they do induce shifts in the endogenous and state-contingent thresholds. In the case of an adverse shock, an increase in these thresholds may lead to the termination of some job-worker matches since $\varepsilon$ can potentially take any value over the range $\left[\varepsilon_{l}, \varepsilon_{u}\right]{ }^{12}$

A worker can be in one of the three following states: unemployed, recently hired or tenured. Each of these states has a corresponding asset value denoted by $V_{u_{i}}$ for unemployment, $V_{o_{i}}$ for a recently-hired outsider, and $V_{e_{i}}$ for a tenured insider. The expected utility stream of a recently-hired worker in state $i$ is given by:

$$
\rho V_{u_{i}}=b+\theta_{i} q\left(\theta_{i}\right)\left[V_{o_{i}}\left(\varepsilon_{u}\right)-V_{u_{i}}\right]+\sum_{i \neq j}^{n} \Omega_{i j}\left[V_{u_{j}}-V_{u_{i}}\right], \forall i, j=1 \ldots n,
$$

where $b$ denotes unemployment benefits. This equation states that unemployed workers find a job at Poisson rate $\theta_{i} q\left(\theta_{i}\right)$, realize capital gains of $\left[V_{o_{i}}\left(\varepsilon_{u}\right)-V_{u_{i}}\right]$ at the time of recruitment, and take into account at Poisson rate $\Omega_{i j}$ the possible changes in aggregate conditions. As previously, EPL requires that we distinguish between the expected utility streams of recentlyhired and tenured workers. The initial value of the match to a worker in state $i$ is:

$$
\begin{aligned}
\rho V_{o_{i}}\left(\varepsilon_{u}\right) & =w_{o_{i}}\left(\varepsilon_{u}\right)+\lambda\left[\int \operatorname{Max}\left[V_{e_{i}}(\zeta), V_{u_{i}}\right] d G(\zeta)-V_{o_{i}}\left(\varepsilon_{u}\right)\right] \\
& +\sum_{i \neq j}^{n} \Omega_{i j}\left[V_{o_{j}}\left(\varepsilon_{u}\right)-V_{o_{i}}\left(\varepsilon_{u}\right)\right], \forall i, j=1 \ldots n .
\end{aligned}
$$

A new worker is paid the outsider wage, $w_{o_{i}}\left(\varepsilon_{u}\right)$, and expects microeconomic and macroeconomic conditions to change with respective Poisson rates $\lambda$ and $\Omega_{i j}$. Finally, the value of continuing

\footnotetext{
${ }^{12}$ Section 2.4 below describes the mechanisms driving job destruction.
} 
the match to the worker in state $i$ is given by:

$$
\begin{aligned}
\rho V_{e_{i}}(\varepsilon) & =w_{i}(\varepsilon)+\lambda\left[\int \operatorname{Max}\left[V_{e_{i}}(\zeta), V_{u_{i}}\right] d G(\zeta)-V_{e_{i}}(\varepsilon)\right] \\
& +\sum_{i \neq j}^{n} \Omega_{i j}\left[\operatorname{Max}\left[V_{e_{j}}(\varepsilon), V_{u_{j}}\right]-V_{e_{i}}(\varepsilon)\right], \forall i, j=1 \ldots n .
\end{aligned}
$$

A tenured worker is paid the insider wage, $w_{i}(\varepsilon)$. The same types of shocks are likely to occur and affect the worker's utility from a tenured match on the labor market. However both sources of turbulence may now produce job terminations, yielding the Max operator in the last term of $(6)$.

\subsection{Surplus, Exit, Entry and Wages}

Surplus: Matches yield a surplus which is equal to the sum of the expected present value of the job to the worker and the employer net of the value of searching for an alternative partner. To derive the key equations necessary to solve the model, it is convenient to define the surplus associated with a job-worker pair. EPL and the related two-tier bargaining structure imply two different definitions of the surplus, depending on whether we consider new matches (during an early negotiation stage) or continuing matches (during a renegotiation stage). Let $S_{o_{i}}\left(\varepsilon_{u}\right)$ and $S_{e_{i}}(\varepsilon)$ be the surplus of new and continuing matches respectively. At the time of recruitment breaking off bargaining entails no separation costs for the firm since no contract has yet been signed. Hence, the surplus of a new match to the job-worker pair contingent on aggregate state $i$ is:

$$
S_{o_{i}}\left(\varepsilon_{u}\right)=V_{o_{i}}\left(\varepsilon_{u}\right)-V_{u_{i}}+\Pi_{o_{i}}(\varepsilon)-\Pi_{v_{i}}
$$

When the worker and the employer clinch a bargain, separation costs take effect if the negotiation fails. As a result, the surplus of a continuing match to the job-worker pair, contingent on aggregate state $i$, is:

$$
S_{e_{i}}(\varepsilon)=V_{e_{i}}(\varepsilon)-V_{u_{i}}+\Pi_{e_{i}}(\varepsilon)-\Pi_{v_{i}}+f+\tau_{e_{i}},
$$

where $f+\tau_{e_{i}}$ represent the costs paid by the firm in the case of separation.

Exit and Entry: The formal condition for proceeding with a match is $S_{e_{i}}(\varepsilon) \geq 0$. Severance between the employer and the employee - job destruction - occurs as soon as idiosyncratic productivity $\varepsilon$ falls below a certain threshold $\varepsilon_{d_{i}}$, after which the surplus becomes negative. The formal condition for severance is:

$$
S_{e_{i}}\left(\varepsilon_{d_{i}}\right)=0
$$


which implicitly defines $\varepsilon_{d_{i}}$ as the minimum idiosyncratic productivity level required to ensure the match's profitability. Job creation is governed by free entry in the matching market. Free entry implies the exhaustion of all rents, and drives the value of holding a vacancy to zero. This latter condition is given by:

$$
\Pi_{v_{i}}=0 .
$$

Wages: Bargaining leads to a surplus-sharing rule $\grave{a}$ la Nash providing a share $\gamma \in[0 ; 1]$ of the surplus to the worker; this can be interpreted as her bargaining power. In the first stage of the negotiation, as separation costs remain virtual, the Nash sharing rule for outsiders is $(1-\gamma)\left[V_{o_{i}}\left(\varepsilon_{u}\right)-V_{u_{i}}\right]=\gamma\left[\Pi_{o_{i}}\left(\varepsilon_{u}\right)-\Pi_{v_{i}}\right]$; in the second stage, where the separation costs take effect, the Nash sharing rule for insiders is $(1-\gamma)\left[V_{e_{i}}(\varepsilon)-V_{u_{i}}\right]=\gamma\left[\Pi_{e_{i}}(\varepsilon)-\left(\Pi_{v_{i}}-f-\tau_{e_{i}}\right)\right]$. Since EPL improves the threat point of the worker, the bargain yields a two-tier wage agreement denoted by $w_{o_{i}}\left(\varepsilon_{u}\right)$ and $w_{i}(\varepsilon)$, given by: ${ }^{13}$

$$
\begin{gathered}
w_{o_{i}}\left(\varepsilon_{u}\right)=(1-\gamma) b+\gamma\left[p_{i}+\sigma \varepsilon_{u}-\tau_{i}+h \theta_{i}-\lambda\left(f+\tau_{e_{i}}\right)\right] \\
w_{i}(\varepsilon)=(1-\gamma) b+\gamma\left[p_{i}+\sigma \varepsilon-\tau_{i}+h \theta_{i}+\rho\left(f+\tau_{e_{i}}\right)+\sum_{i \neq j}^{n} \Omega_{i j}\left(\tau_{e_{i}}-\tau_{e_{j}}\right)\right] .
\end{gathered}
$$

It is worth noting that EPL produces a gap between insiders' and outsiders' wages. The explanation is intuitive. On the first tier, outsiders are prepared to concede a wage-cut in order to benefit from EPL later on, hence the negative term, $-\lambda\left(f+\tau_{e_{i}}\right)$, in (11). Conversely, on the second tier, insiders use EPL to capture a greater part of the rent, hence the positive term, $\rho\left(f+\tau_{e_{i}}\right)$, in (12). These two effects are nevertheless common to the majority of EPL models with flexible wage-setting. More interestingly, wages appear to take into account the change in the layoff tax with aggregate conditions. Thus the second EPL component contrasts strongly with the first one $-f$ in our model - in the sense that the layoff tax is state-contingent.

\subsection{Creation and Destruction of Job-Worker Matches}

Using the entry and exit conditions, and the definitions of the surplus, we derive the two key relationships required to define the equilibrium. These will be referred to hereafter as the job creation and job destruction conditions. ${ }^{14}$

Job Destruction: Separation between the worker and the firm takes place as soon as the rent from the match drops to zero. The formal condition is given by the exit condition (9). Some

\footnotetext{
${ }^{13}$ See Appendix 1 for the details of these calculations.

${ }^{14}$ See Appendix 2 for details of these calculations.
} 
algebra yields the job destruction condition for state of nature $i$. The job destruction threshold is written as:

$$
\begin{aligned}
p_{i}+\sigma \varepsilon_{d_{i}} & =b+\frac{\theta_{i} \gamma h}{1-\gamma}+\tau_{i}-\rho\left(\tau_{e_{i}}+f\right)-\lambda E\left(S_{e_{i}}\right) \\
& -\sum_{i \neq j}^{n} \Omega_{i j}\left(\tau_{e_{i}}-\tau_{e_{j}}\right)-\sum_{i \neq j}^{n} \Omega_{i j}\left[\operatorname{Max}\left[S_{e_{j}}\left(\varepsilon_{d_{i}}\right), 0\right]\right],
\end{aligned}
$$

where $E\left(S_{e_{i}}\right)=\int \max \left[S_{e_{i}}(\zeta), 0\right] d G(\zeta)$ stands for the expected value of the surplus in aggregate state $i$. The RHS of (13) shows that reservation productivity depends on the opportunity cost of employment, $b+\theta_{i} \gamma h /(1-\gamma)+\tau_{i}$, which is the sum of unemployment benefits, the expected value of search and the lump-sum payroll tax. Layoffs are influenced by both aggregate and idiosyncratic shocks. In both cases, as soon as the surplus of a job-worker match is non-positive, there is no incentive to pursue the employment relationship. The job-worker match is subject to two sources of productivity shocks (idiosyncratic and aggregate).

The figure below illustrates how job destruction works in our framework. The cutoff productivities, $\varepsilon_{d_{i}}, \forall i=1 \ldots n$, are ranked in descending order, where subscript 1 stands for the best aggregate state and subscript $n$ for the worst.

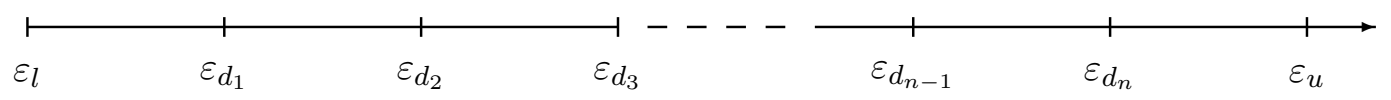

Figure 1: Reservation (cutoff) productivities contingent on aggregate state $i, \forall i=1 \ldots n$.

A job-worker match is destroyed for one of two reasons. First, at given aggregate productivity, there are idiosyncratic shocks. Job-specific productivity changes at a Poisson rate of $\lambda$, in which case the firm compares the option value of dissolving the match to the value of pursuing the employment relationship. In the event of such a shock a new value of the job-specific productivity is drawn from the general distribution $G$. According to the current endogenous productivity threshold, $\varepsilon_{d_{i}}$, the job is destroyed if the new value of productivity is below this cutoff productivity. This is the usual microeconomic (firm-specific) source of job destruction. Second, at a given idiosyncratic productivity level, there are aggregate shocks. A change in macroeconomic conditions causes cutoff productivity to shift up (in the case of an adverse shock) or down (in the case of a good shock). In other words, a positive shock unveils a new range of productive jobs (say from $\varepsilon_{d_{n}}$ to $\varepsilon_{d_{n-1}}$ ) whereas an adverse shock retires an old range 
of previously productive jobs (say from $\varepsilon_{d_{n-1}}$ to $\varepsilon_{d_{n}}$ ). This is the macroeconomic (economywide) source of job destruction. More accurately, following an adverse aggregate shock, the expected profit associated with any job-worker match falls. Firms become pickier and, as a consequence, the destruction threshold moves up, leading to an increase in the job destruction rate. Conversely, following a positive aggregate shock, the profit associated with any job-worker match increases. Firms become less demanding and consequently the destruction threshold shifts downwards, leading to a decrease in job destruction.

It is also worth remarking from equation (13) that reservation productivity is lower than the opportunity cost of employment. This phenomenon stems from labor hoarding. In our framework there are four natural sources of labor hoarding. First, at the microeconomic level (for a given aggregate state), there are two sources of retention. First, an institutional source captured by the term, $\rho\left(\tau_{e_{i}}+f\right)$, representing the capitalized value of dismissal costs which induces firms to reduce the productivity threshold and retain more workers. The state-contingent layoff tax has a direct standard EPL effect by enhancing this institutional source of labor hoarding. Up to this point the layoff tax behaves exactly as a standard EPL component. Second, a voluntary source captured by the term $\lambda E\left(S_{e_{i}}\right)$, corresponding to the option value of maintaining a job-worker match due to the expected change in idiosyncratic productivity $\varepsilon$. In addition, our framework encompasses two macroeconomic sources of labor hoarding. First, an institutional source captured by the term $\sum_{i \neq j}^{n} \Omega_{i j}\left(\tau_{e_{i}}-\tau_{e_{j}}\right)$, underlining that the layoff tax is state-contingent. Hence, an expected increase in these costs gives firms an incentive to terminate more jobs in the current state to avoid higher termination costs later on. Second, a voluntary source captured by the term $\sum_{i \neq j}^{n} \Omega_{i j}\left[\operatorname{Max}\left[S_{e_{j}}\left(\varepsilon_{d_{i}}\right), 0\right]\right]$, indicating expected labor hoarding following a shift in aggregate conditions.

At this stage, it is important to remark that this aggregate voluntary source of labor hoarding is asymmetric between states. Two polar cases illustrate this point. First assume that the economy is in the best aggregate state. Here aggregate conditions can only worsen, leading to an increase in the productivity threshold. Job-worker matches with a current productivity below the future productivity threshold are therefore expected to be destroyed and have zero expected surplus $\left(S_{e_{j}}\left(\varepsilon_{d_{i}}\right)=0\right)$. Second, assume that the economy is in the worst aggregate state. Here aggregate conditions can only improve, leading to a decrease in the productivity threshold. Hence all job-workers matches are preserved and are expected to yield greater surplus as aggregate conditions shift. It follows that the fourth labor hoarding component is greater the worse are aggregate conditions. 
Job Creation: Firms enter the labor market until all profit opportunities from new jobs have been exploited. In equilibrium, the rents from vacant jobs are zero and satisfy the free-entry condition (10). Some algebra produces the job creation condition for state of nature $i$. This condition which defines labor-market tightness is written as:

$$
\begin{aligned}
\frac{h(\rho+\lambda)}{q\left(\theta_{i}\right)} & =(1-\gamma)\left[p_{i}+\sigma \varepsilon_{u}-\tau_{i}-b-\frac{\theta_{i} \gamma h}{1-\gamma}\right]-(1-\gamma) \lambda\left(\tau_{e_{i}}+f\right)+(1-\gamma) \lambda E\left(S_{e_{i}}\right) \\
& +\sum_{i \neq j}^{n} \Omega_{i j}\left[\frac{h}{q\left(\theta_{j}\right)}-\frac{h}{q\left(\theta_{i}\right)}\right] .
\end{aligned}
$$

This equation simply states that the expected value of search cost has to equal the expected profit of a new job to the firm. The LHS of (14) represents the expected capitalized value of the firm's hiring cost in the current state. This cost increases in labor market tightness, $\theta_{i}$, as the higher is market tightness, the longer the time it takes to fill a vacancy. The RHS of (14) stands for the expected profit of a vacant job. This expected profit decreases in labor market tightness because the utility of the unemployed increases in labor market tightness. In other words market tightness improves workers' outside opportunities and translates into higher reservation wages. The RHS of (14) can be divided into four terms: (i) the net instantaneous flow profit, $p_{i}+\sigma \varepsilon_{u}-\tau_{i}-b-\frac{\theta_{i} \gamma h}{1-\gamma}$; (ii) the expected loss to the firm due to contract renegotiation following an idiosyncratic productivity shock, $\lambda\left(\tau_{e_{i}}+f\right) 1^{15}$ (iii) the option value of retaining a job-worker match, $\lambda E\left(S_{e_{i}}\right)$; and (iv) the expected change in the profit following a change in the aggregate conditions, $\sum_{i \neq j}^{n} \Omega_{i j}\left[\frac{h}{q\left(\theta_{j}\right)}-\frac{h}{q\left(\theta_{i}\right)}\right]$.

\subsection{Balanced-Budget Rule and Fiscality}

Budget Rule: To close the model, we need to connect unemployment benefits to their financing. For solvency reasons, the government needs to respect a balanced-budget rule and cannot independently set unemployment benefits and the taxes required to finance them. Accordingly, the level of unemployment benefits is exogenous whereas the taxes collected to finance unemployment insurance are endogenous and ensure a balanced budget in each aggregate state. ${ }^{16}$ Unemployment benefits are financed by two instruments: a lump sum payroll tax $\tau_{i}$ paid on each filled job, and a tax paid each time a job is destroyed, denoted by $\tau_{e_{i}}$. This second tax is introduced in order to take the budgetary effects of the state-contingent layoff tax into account. The coverage of the layoff tax is said to be complete or perfect when $\tau_{i}=0$, i.e. when the firm supports the entire cost of the expenditure created via its firing decisions. Conversely, the tax

\footnotetext{
${ }^{15}$ Note that the state-contingent layoff tax in increasing the contract renegotiation cost behaves in a standard EPL way, hence lowering job creation

${ }^{16} \mathrm{An}$ alternative specification of the budget rule is considered in Section 3.3.
} 
is said to be perfectly incomplete or imperfect when $\tau_{e_{i}}$ is nil, i.e. unemployment benefits are exclusively financed through the lump-sum payroll tax. It is important to note that this latter case is consistent with the financing of unemployment benefits in almost all OECD countries. In all other cases, the layoff tax is said to be incomplete. The balanced-budget rule implies:

$$
\left(1-u_{i}\right) \tau_{i}+\left(1-u_{i}\right) \lambda G\left(\varepsilon_{d_{i}}\right) \tau_{e_{i}}=u_{i} b
$$

where $u_{i} b$ denotes (endogenous) expenditures on unemployment compensation. Resources are equal to the sum of the payroll tax $\left(1-u_{i}\right) \tau_{i}$ - the mutualized part of unemployment benefitsand the layoff tax $\left(1-u_{i}\right) \lambda G\left(\varepsilon_{d_{i}}\right) \tau_{e_{i}}$. This last term depends on the job-destruction rate. Accordingly, the greater are layoffs, the higher is the firm's contribution to the financing system.

Lump Sum Payroll Tax: We can use (15) to determine the endogenous lump sum tax, $\tau_{i}$ :

$$
\tau_{i}=\frac{u_{i}}{1-u_{i}} b-\lambda G\left(\varepsilon_{d_{i}}\right) \tau_{e_{i}} .
$$

One crucial property of the above is that $\tau_{i}$ is decreasing in $\tau_{e_{i}}$. The state-contingent layoff tax makes firms partly defray the fiscal costs they produce through their firing decisions. Any increase in the layoff tax makes firms directly bear a greater part of this fiscal cost. Consequently, the mutualized part of the fiscal cost falls with the layoff tax. The layoff tax thus has a fiscal impact which is absent from the usual EPL programmes. The introduction of a layoff tax tightens the strictness of EPL but at the same time reduces the mutualized part of unemployment benefits and the lump-sum payroll tax. It follows that this fall in the payroll tax will increase the profitability of any job.

State-contingent layoff tax: In the event of separation, the tax incurred by the firm is determined according to a fiscal-cost criterion. The fiscal cost of an unemployed worker, $C_{i}$, is given by the following arbitrage equation:

$$
\rho C_{i}=b+\theta_{i} q\left(\theta_{i}\right)\left[0-C_{i}\right]+\sum_{i \neq j}^{n} \Omega_{i j}\left[C_{j}-C_{i}\right],
$$

where $C_{i}$ is the expected fiscal cost. An unemployed worker receives instantaneous income of $b$ and returns to employment with a transition rate $\theta_{i} q\left(\theta_{i}\right)$. When she returns to employment, her fiscal cost to the unemployment compensation system is zero. In addition, note that this cost will likely change with aggregate conditions. Let $e \in[0 ; 1]$ be an index of the coverage of the layoff tax, i.e. the percentage of the expected fiscal cost that is directly borne by the firm at the time of the layoff. We will refer to this equivalently as the degree or the index of the layoff 
tax in the reminder of the paper. It follows that the state-contingent layoff tax incurred by the firm amounts to $\tau_{e_{i}}=e C_{i}$ for $i=1 \ldots n$. Substituting this last expression into (17), we have:

$$
\tau_{e_{i}}=\frac{e b+\sum_{i \neq j}^{n} \Omega_{i j} \tau_{e_{j}}}{\rho+\theta_{i} q\left(\theta_{i}\right)+\sum_{i \neq j}^{n} \Omega_{i j}} .
$$

In partial equilibrium, it is henceforth possible to establish the following properties for the layoff tax defined by (18):

- (i) The layoff tax increases in unemployment benefits, $b$. The higher are unemployment benefits the higher is the overall cost of a worker on the dole to the firm for any positive value of the index;

- (ii) The layoff tax increases in the layoff-tax index, e. A higher value of this index lowers the mutualized part of unemployment benefits and therefore raises the cost incurred by the firm;

- (iii) The layoff tax decreases in labor-market tightness, $\theta_{i}$. Greater labor-market tightness increases the exit rate from unemployment and consequently shortens unemployment spells. As a result, the expected fiscal cost is smaller, hence so is the cost borne by the firm.

It is worth remarking that all of the above properties are characteristic of the U.S. experiencerating system. The major difference between our state-contingent layoff tax and such a system is that in an experience-rated system, the tax is paid over time rather than at the time of the layoff.

It is also important to note that, contrary to firing costs, the layoff tax is state-contingent, being higher the poorer are aggregate conditions. A rise in the layoff-tax index then translates into a fall in payroll tax that will be all the more pronounced the better are aggregate conditions. It follows that as the layoff-tax index rises, the balanced-budget rule induces a smoothing effect of the same type that a constant payroll tax over the business cycle would have generated.

\subsection{Flow Equilibrium}

Given the aggregate state $i$, labor market tightness, $\theta_{i}$, and the productivity threshold, $\varepsilon_{d_{i}}$, the equilibrium unemployment rate, $u_{i}$, evolves as a function of the job destruction rate $\lambda G\left(\varepsilon_{d_{i}}\right)$ and the exit rate from unemployment $\theta_{i} q\left(\theta_{i}\right)$. The law of motion of unemployment in the labor market in state $i$ satisfies:

$$
\frac{d u_{i}}{d t}=\lambda G\left(\varepsilon_{d_{i}}\right)\left(1-u_{i}\right)-\theta_{i} q\left(\theta_{i}\right) u_{i}
$$


Equation (19) is the key to understanding the behavior of unemployment when the economy is in state $i$. When the economy is hit by an aggregate shock, labor-market tightness, $\theta_{i}$, and the productivity threshold, $\varepsilon_{d_{i}}$, jump to their new values and the unemployment rate adjusts consequently.

If the aggregate component of productivity, $p_{i}$, repeatedly takes on the same value, the economy converges to a state with constant unemployment. In line with Cole and Rogerson (1999), if we assume a long sequence of such aggregate productivity shocks, the stationary and conditional unemployment rate, $\tilde{u}_{i}$, is obtained from the stock-flow condition for constant unemployment as:

$$
\tilde{u}_{i}=\frac{\lambda G\left(\varepsilon_{d_{i}}\right)}{\lambda G\left(\varepsilon_{d_{i}}\right)+\theta_{i} q\left(\theta_{i}\right)} .
$$

This last equation is only valid in the steady state in the absence of any aggregate turbulence. It expresses the equilibrium of worker flows between employment and unemployment, given the properties of the matching function, and yields the Beveridge curve. It is decreasing in labor-market tightness and increasing in reservation productivity.

\subsection{Equilibrium}

Definition: In each state equilibrium for a given labor market policy $(e ; f)$ is defined by a n-tuple $\left(\varepsilon_{d_{i}}, \theta_{i}, \tau_{i}, \tau_{e_{i}}, u_{i}\right)$ composed of reservation productivity, labor-market tightness, the payroll tax, the state-contingent layoff tax and the equilibrium unemployment rate. This vector solves the set of equations defined by (13), (14), (16), (18) and (20). Formally the system is as follows:

(i) Reservation Productivity

$$
\begin{aligned}
p_{i}+\sigma \varepsilon_{d_{i}} & =b+\theta_{i} \frac{\gamma}{1-\gamma} h+\tau_{i}-\rho\left(\tau_{e_{i}}+f\right)-\lambda E\left(S_{e_{i}}\right) \\
& -\sum_{i \neq j}^{n} \Omega_{i j}\left(\tau_{e_{i}}-\tau_{e_{j}}\right)-\sum_{i \neq j}^{n} \Omega_{i j}\left[\operatorname{Max}\left[S_{e_{j}}\left(\varepsilon_{d_{i}}\right), 0\right]\right],
\end{aligned}
$$

(ii) Labor-Market Tightness

$$
\begin{aligned}
\frac{h(\rho+\lambda)}{q\left(\theta_{i}\right)} & =(1-\gamma)\left[p_{i}+\sigma \varepsilon_{u}-\tau_{i}-b-\theta_{i} \frac{\gamma}{1-\gamma} h-\lambda\left(\tau_{e_{i}}+f\right)+\lambda E\left(S_{e_{i}}\right)\right] \\
& +\sum_{i \neq j}^{n} \Omega_{i j}\left[\frac{h}{q\left(\theta_{j}\right)}-\frac{h}{q\left(\theta_{i}\right)}\right],
\end{aligned}
$$

(iii) The Payroll Tax

$$
\tau_{i}=\frac{u_{i}}{1-u_{i}} b-\lambda G\left(\varepsilon_{d_{i}}\right) \tau_{e_{i}}
$$


(iv) The State-Contingent Layoff Tax

$$
\tau_{e_{i}}=\frac{e b+\sum_{i \neq j}^{n} \Omega_{i j} \tau_{e_{j}}}{\rho+\theta_{i} q\left(\theta_{i}\right)+\sum_{i \neq j}^{n} \Omega_{i j}},
$$

(v) The Law of Motion of Unemployment

$$
\frac{d u_{i}}{d t}=\lambda G\left(\varepsilon_{d_{i}}\right)\left(1-u_{i}\right)-\theta_{i} q\left(\theta_{i}\right) u_{i}
$$

This system defines the equilibrium key values in each aggregate state $i$. The model consists of $5 n$ non-linear equations to be jointly solved to compute the equilibrium. Given its complexity the model cannot be solved analytically under its general form, hence the necessity to turn to numerical simulations. ${ }^{17}$

\section{A General Equilibrium Perspective}

\subsection{The Benchmark Economy and Calibration}

To derive quantitative conclusions, the model needs to be calibrated. The data parameters and moments used in the calibration refer to the French economy. The period is the quarter and the discount rate, $\rho$, is set to $1 \%$. A Cobb-Douglas matching function is assumed such that $M\left(u_{i}, v_{i}\right)=k u_{i}^{\alpha} v_{i}^{1-\alpha}$, where $k$ is a mismatch parameter and $\alpha$ and $1-\alpha$ are the elasticities of the matching function with respect to search inputs. We assume $\alpha$ to be equal to 0.5 , which is in the range of the estimates obtained by Petrongolo and Pissarides (2001), and more specifically Fève and Langot (1996) for the French labor market. We assume equal bargaining power between firms and workers. The distribution of idiosyncratic shocks is assumed to be uniform over the support $\left[\varepsilon_{l}, \varepsilon_{u}\right]$. Following Gomes et al. (2001) the properties of the aggregate technology shock are summarized by a three-point Markov chain on the set $\left(p_{1}, p_{2}, p_{3}\right)$ where the state-to-state transition probabilities $\Omega_{i j}, \forall i, j=1,2,3$ are ranked in the matrix $\Omega$. This chain is chosen to approximate an autoregressive (AR) process of the form $y_{t}=\phi y_{t-1}+v_{t}$, where $\phi$ and $v$ respectively refer to the autocorrelation coefficient and the standard error of the innovation. Using French data over the period 1970-1996, Karamé (2000) estimated these parameters as $\phi=0.94$ and $v=0.007$. The vector of aggregate productivity components $\left(p_{1}, p_{2}, p_{3}\right)$ is set to match the mean and variance of the underlying AR process. Assuming that it is impossible to

\footnotetext{
${ }^{17}$ In addition, the model may exhibit multiple equilibria. As pointed out by Rocheteau (1999), the existence of multiple equilibria is a generic property of search and matching economies with balanced-budget rules. As a consequence, we cannot rule out here the occurrence of such equilibria. However, we argue that this not a problem since the government is able (through proper fiscal instruments) to choose the low-unemployment equilibrium and therefore to avoid any pathological equilibria.
} 
jump from one extreme state to another, the state-to-state transition matrix is:

$$
\left[\Omega_{i j}\right]=\left[\begin{array}{ccc}
\phi & 1-\phi & 0 \\
\frac{1-\phi}{4} & \frac{1+\phi}{2} & \frac{1-\phi}{4} \\
0 & 1-\phi & \phi
\end{array}\right]=\left[\begin{array}{ccc}
0.94 & 0.06 & 0 \\
0.015 & 0.97 & 0.015 \\
0 & 0.06 & 0.94
\end{array}\right]
$$

The vector of aggregate productivity components associated with this matrix satisfies $\left(p_{1}, p_{2}, p_{3}\right)=$ $(0.0355,0,-0.0355)$, where the subscripts 1,2 and 3 stand for the high, median and low aggregate states respectively. The idiosyncratic dispersion indicator $\sigma$ is set so as to reproduce a relative variance between the aggregate and the idiosyncratic shocks in the range previously found by Karamé (2000) on French data and Den Haan et al. (2000) and Gomes et al. (2001) on U.S. data. The key feature is that the contribution of idiosyncratic productivity to total productivity variation is much more important than the contribution of aggregate productivity (Davis and Haltiwanger, 1999).

Since there is no state-contingent layoff tax in the French labor market, the index, $e$, is set to zero in the benchmark economy. The level of the red tape and legal costs, $f$, is set to represent $50 \%$ of the average annual wage in the steady state. This level is consistent with the findings of French empirical studies described, for instance, by Kramarz et al. (2004). Unemployment benefits are set to $60 \%$ of the average long-term wage, which is in the range of OECD estimates.

The remaining free parameters, $k, \lambda$ and $h$ are chosen in order to match key characteristics of the French labor market. Specifically, the scale parameter $k$ and the cost of vacant jobs $h$ are set to yield a mean unemployment rate of $10.6 \%$ and to be consistent with the average cost of posting a vacancy as documented by Kramarz et al. (2004). From an empirical point of view, it is difficult to disentangle the arrival shocks rate $\lambda$ from the reservation productivity $\varepsilon_{d_{i}}$. Accordingly, $\lambda$ is calibrated so as to represent an average job destruction rate of $5.5 \%$ per quarter, in the range of values reported by Duhautois (2002). The parameter values used in the computations are summarized in Table 1.

\begin{tabular}{lcc|lcc}
\hline \hline Variable & Notation & Value & Variable & Notation & Value \\
\hline Matching elasticity & $\alpha$ & 0.5 & Mismatch parameter & $k$ & 1 \\
Bargaining power & $\gamma$ & 0.5 & Discount rate & $\rho$ & 0.01 \\
Dispersion indicator & $\sigma$ & 0.3637 & Vacancy cost & $h$ & 0.37 \\
Shock arrival rate & $\lambda$ & 0.8 & Firing cost & $f$ & 0.572 \\
Autocorrelation coefficient & $\phi$ & 0.94 & Unemployment benefits & $b$ & 0.1716 \\
Innovation & $v$ & 0.007 & Layoff tax index & $e$ & 0 \\
\hline \hline
\end{tabular}

Table 1: Baseline Parameters for the French Labor Market. 


\subsection{Employment Protection Reform}

Methodology: In order to assess the properties of the state-contingent layoff tax, we consider the effects of an EPL reform which consists of a perfect substitution between the firing cost, $f$, and the state-contingent layoff tax, $\tau_{e_{i}}$. This substitution implies the same ex post long-term degree of employment protection in the median aggregate productivity state. Formally, the vector of policies that satisfies this substitution is given by $\left(\tau_{e}=0.2, f=0.372, e=0.6540\right){ }^{18}$ In order to gauge the effect of the reform, three criteria are used: the unemployment rate, production and the budget size (as a percentage of total production). We focus on dynamic analysis so as to shed light on the cyclical properties of EPL reform. To this end we use the laws of motion of the key labor market variables (see the Appendix), to build time series for each variable, and calculate the relevant statistics, namely the mean, the standard deviation and the correlation coefficient. To obtain these statistics ${ }^{19}$ we simulate the model for 500 periods and discard the first 100 observations to avoid problems pertaining to initial dependance. The remaining 400 observations are then logged and filtered using the Hodrick-Prescott filter. We repeat this procedure 100 times and compute averages over the 100 samples. $^{20}$

Cyclical Properties: As a preamble, and before inspecting the effects of the reform, we present the main cyclical properties of the French labor market, as well as the simulated equivalents, in order to assess the capacity of the model to fit the data. Table 2 summarizes the results. While

\begin{tabular}{lcc}
\hline \hline & French Data & Benchmark Economy \\
\hline$\sigma_{J C}$ & 0.21 & 0.21 \\
$\sigma_{J D}$ & 0.30 & 0.25 \\
$\operatorname{Cor}(J C, J D)$ & -0.65 & -0.60 \\
$\sigma_{u}$ & 0.83 & 0.55 \\
$\operatorname{Corr}(u, v)$ & -0.20 & -0.11 \\
\hline \hline
\end{tabular}

Table 2: Main cyclical properties of the French labor market: comparison to the benchmark economy. Sources: Duhautois (2002), Karamé (2000) and authors' calculations.

the cyclical properties of the benchmark economy fit the French data as reported by Karamé (2000) and Duhautois (2002) fairly well, we may be puzzled by the low correlation between $u$ and $v$ in the case of the benchmark economy, which is far removed from the corresponding figure for the U.S.. economy. ${ }^{21}$ It should be noted that the empirical correlation between the two variables is in fact much lower in France than in the U.S. Even so, some discrepancy remains between

\footnotetext{
${ }^{18}$ This number is in the range of the average experience-rating index in the U.S. economy over $1988-1997$ (UIPL, 1999) and is therefore deemed to be realistic.

${ }^{19}$ In the remainder of the paper $\bar{x}$ and $\sigma_{x}$ stand respectively for the mean and the standard deviation of $x$.

${ }^{20} \mathrm{It}$ is worth noting that the qualitative results of the model, and particularly the cyclical properties, do not depend on this procedure.

${ }^{21}$ We are grateful to an associate editor for pointing out this fact.
} 
the two correlations $(u, v)$, as indicated in the last row of Table 2. This echoes an ongoing and lively debate over the capacity of the search and matching framework to replicate the cyclical behavior of unemployment and vacancies in the U.S. This debate originated in an influential paper by Shimer (2005), giving rise to what Pissarides (2007) has called the "unemployment volatility puzzle" 22 . While this debate is fascinating, it remains beyond the scope of the current paper for two reasons: (i) the volatility puzzle seems somewhat less important in the French labor market; and (ii) the focus of this paper is on the variation in rather than the level of the model's cyclical properties induced by EPL reform.

EPL Reform: Tables 3 and 4 present the main results of our numerical simulations. The first part of Table 3 shows the effects of the reform over the business cycle on the means of the relevant variables (namely job creation, job destruction, the unemployment rate and production), whereas the second part presents the standard deviations. Table 4 focuses on the effects of reform on the unemployment rate and budget size for each aggregate state. From Table 3, it is evident that, on

\begin{tabular}{cccccc}
\hline \hline & Benchmark & EPL Reform & & Benchmark & EPL Reform \\
\hline$\overline{J C}$ & 5.4908 & 5.4742 & $\sigma_{J C}$ & 0.2176 & 0.1735 \\
$\overline{J D}$ & 5.4903 & 5.4738 & $\sigma_{J D}$ & 0.2491 & 0.1359 \\
$\bar{u}$ & 10.6951 & 10.0450 & $\sigma_{u}$ & 0.5480 & 0.3966 \\
$\bar{Y}$ & 28.1615 & 29.0954 & $\sigma_{Y}$ & 1.4336 & 1.2812 \\
\hline \hline
\end{tabular}

Table 3: Simulation Statistics for 100 series of 400 quarters. Means and standard deviations for job creation, job destruction, the unemployment rate and production. The data are logged and HP filtered.

average, the reform reduces both job creation and job destruction. The unemployment rate also unambiguously falls by about 0.65 percentage points. It follows that the fall in unemployment leads to a stabilization of budget size (see Table 4), an indicator of unemployment benefit finance. It is also worth remarking that production increases slightly, which we can impute to the fact that we have substituted a resource-maintaining policy (a tax to finance the UI system) for a resource-destroying policy (a pure administrative firing cost). We return to this issue in the last part of the paper. Table 4 offers further insights by disentangling the effects of the reform by aggregate state. For each aggregate state, both the unemployment rate and the budget (as a percentage of production) fall. Hence, the results underlined in the previous table are not only valid on average but also in each aggregate state. In addition, Table 4 allows us to infer the cyclical properties of the reform. As can be seen in the last column, the effects of the reform are more pronounced in worse aggregate conditions.

\footnotetext{
${ }^{22}$ Recent contributions have tried to solve this puzzle to make the model fit the U.S. data better. To name but a few, see Hall and Milgrom (2008), Mortensen and Nagypal (2007) and Yashiv (2006).
} 


\begin{tabular}{ccccc}
\hline \hline Variable & State & Benchmark & EPL Reform & Net Variation \\
\hline \multirow{3}{*}{ Unemployment } & High & $9.10 \%$ & $8.80 \%$ & -0.30 \\
& Median & $10.57 \%$ & $9.96 \%$ & -0.61 \\
& Low & $12.75 \%$ & $11.58 \%$ & -1.17 \\
\hline \multirow{3}{*}{ Budget } & High & $4.97 \%$ & $4.65 \%$ & -0.32 \\
& Median & $6.57 \%$ & $5.94 \%$ & -0.63 \\
& Low & $8.09 \%$ & $7.33 \%$ & -0.76 \\
\hline \hline
\end{tabular}

Table 4: Simulation Statistics for 100 series of 400 quarters. Mean unemployment rate and mean budget size (in percentage of the production) for each aggregate state.

We can now be more specific about how the state-contingent layoff tax works in this model. The tax has two effects on job creation and job destruction: (i) a standard EPL effect; and (ii) a fiscal effect. The first effect acts exactly as an EPL device. A higher tax increases turnover costs, promoting labor hoarding. As a result, the job destruction rate falls. At the same time, the expected profits on new jobs fall. It follows that job creation is also reduced. Hence, with the reform the two EPL components offset each other on average. There is however a fiscal counterpart to the layoff tax - the fiscal effect - as the tax serves to finance unemployment insurance. It follows that the layoff tax reduces the share of unemployment benefits whose financing is mutualized, since $\tau_{i}$ decreases in $\tau_{e_{i}}$. The cost of labor is therefore lower, the profit associated with any job higher, and so the fiscal effect unveils a new range of productive matches. The layoff tax brings about a sharper decrease in the productivity threshold than do firing costs, and consequently an additional degree of labor hoarding.

The overall effect of the layoff tax results from the combination of these two channels. The cyclical dependence of EPL has multiple consequences for both job destruction and job creation (see equations 13 and 14). An increase in the layoff tax index induces changes in the fiscal components, $\tau_{e}$ and $\tau$, which are all the more pronounced in a depressed macroeconomic environment. It follows that firms retain more workers towards the bottom of the cycle. Put differently, the fall in reservation productivity is greater the worse are aggregate conditions. The overall effect of an increase in the index on job creation is a little more tedious to draw out since both fiscal variables have contradictory effects on tightness. Our numerical experimentations do allow us however to show that for reasonable parameter values the - favorable - fiscal effect outweighs the - adverse - EPL effect in each aggregate state. Further, the net effect on tightness is more pronounced in depressions. In other words, the elasticity of job creation to the statecontingent layoff tax is lower than the elasticity of job creation to the payroll tax, and this gap is larger in worse macroeconomic conditions. Finally, taking the effects of the tax on both job destruction and job creation into account, the unemployment rate falls in all states, and more 
so in worse aggregate conditions. It is important to note that this result has been shown to be robust to several different model specifications.

The mechanisms we discussed above are consistent with the result presented in the second part of Table 3. Looking back to the latter, it is evident that EPL reform tends to lower the standard deviation of both job creation, $\sigma_{J C}$, and job destruction, $\sigma_{J D}$. In other words, the state-contingent layoff tax tends to reduce the variability of job flows and consequently to stabilize the labor market. The key result of this table relates however to the connection between the state-contingent layoff tax and aggregate employment fluctuations. Table 3 shows that EPL reform reduces aggregate employment variability by about $25 \%$ ( $\sigma_{u}$ drops from 0.55 to 0.40 ). The layoff tax acts therefore as a strong employment stabilizer. It is also worth remarking that the standard deviation of production also falls, although to a smaller extent ( $\sigma_{Y}$ drops from 1.43 to 1.28$)$.

The results thus support a state-contingent layoff tax and refute the assertion that such a system (which borrows from the U.S. experience-rating system) acts exactly as a common EPL device. It is also worth noting that our results corroborate and extend the steady-state analysis in Cahuc et al. (2004) to a general dynamic framework with macroeconomic turbulence.

\subsection{Robustness and Discussion}

To further highlight the effects of the reform, we now discuss in more depth some issues relative to the robustness ${ }^{23}$ of the model. Specifically, we pay particular attention to alternative specifications of the balanced-budget rule as well as to the manner in which firing costs (red tape and legal costs) affect the economy.

Fiscality: In the core of the paper, unemployment insurance is balanced in each aggregate state. Alternatively, we may consider the case where the government chooses to adjust the payroll tax on average over the business cycle. This point is important, since the tax may then serve as an instrument to smooth employment. Under this specification, payroll taxes tend to be lower than the adjusted payroll tax in bad aggregate states and higher in good aggregate states, hence smoothing employment over the cycle. The simulation results for this specification are presented in Table 5.

The results appear to be robust to this specification. Comparing Tables 3 and 5, we see that

\footnotetext{
${ }^{23}$ The results of the model appear to be robust to a wide range of specifications. Besides the issues raised here, we have considered alternative numerical exercises (not reported here for space considerations) notably by increasing the layoff-tax index (for a constant value of the firing costs, $f$ ) from $e=0$ - the benchmark valueto $e=0.65$ - the average value in the previous simulations, and by iterating the degree of persistency, $\phi$, of the aggregate shocks over the plausible range $\phi \in[0.91 ; 0.97]$. The qualitative results of the model remain valid whatever the specification. The results are available upon request from the authors.
} 


\begin{tabular}{cccccc}
\hline \hline & Benchmark & EPL Reform & & Benchmark & EPL Reform \\
\hline$\overline{J C}$ & 5.4877 & 5.4737 & $\sigma_{J C}$ & 0.1944 & 0.1667 \\
$\overline{J D}$ & 5.4872 & 5.4734 & $\sigma_{J D}$ & 0.2265 & 0.1317 \\
$\bar{u}$ & 10.6558 & 10.0358 & $\sigma_{u}$ & 0.4881 & 0.3812 \\
$\bar{Y}$ & 28.1450 & 29.0921 & $\sigma_{Y}$ & 1.3616 & 1.2595 \\
\hline \hline
\end{tabular}

Table 5: Balanced-budget and constant payroll taxes over the business cycle. Simulation Statistics for 100 series of 400 quarters. Mean and standard deviation for the job creation, job destruction, the unemployment rate and production. The data are logged and HP filtered.

the volatility of unemployment falls from 0.54 to 0.48 in the benchmark case while the average unemployment rate remains constant. A constant payroll tax may be seen as a more natural way in which to smooth employment. However, the results in Tables 3 and 5 suggest that this effect is greater under the EPL reform whatever the balanced-budget rule. In fact the standard deviation of unemployment is about 0.38 under both specifications, while the average unemployment rate is significantly lower. Finally, we conclude that the model results remain whatever the balanced-budget rule, hence proving that the state-contingent layoff tax is a strong smoothing instrument.

Firing Costs: Until now we have supposed that firing costs are real resource costs reducing overall production in the economy. This hypothesis introduces an asymmetry between the benchmark case and the EPL reform, ${ }^{24}$ since the state-contingent layoff tax serves as a means of financing the UI system, i.e. the reform substitutes a resource-maintaining policy for a resourcedestroying policy. It follows that the EPL reform will necessarily increase production due to the fiscal effect depicted previously. In order to filter out the fiscal effect, we now suppose that the red tape and legal costs also serve as a means of financing the UI system. ${ }^{25}$ As a result the only remaining difference between the benchmark case and the EPL reform pertains to the state-contingency of the layoff tax. Table 6 provides the simulation results when the asymmetry between the benchmark case and the EPL reform is dropped. The comparison of Tables 3 and 6 shows that the fiscal counterpart of layoff taxes has a strong impact on unemployment and production. The former drops from $10.69 \%$ to $9.17 \%$ while the latter increases from 28.16 to 30.94. It follows that the fall in the unemployment rate observed in Table 3 is essentially due to the fiscal effect, i.e. to the substitution of a resource-destroying policy by a resource-maintaining policy. Hence, a reform which substitutes a constant layoff tax for a state-contingent layoff tax has no significant impact on employment (in Table 6, mean unemployment only falls by about

\footnotetext{
${ }^{24}$ We are grateful to a referee for pointing out this important issue.

${ }^{25}$ Note that this specification is only illustrative, and has no general counterpart in the real world, since red tape and legal costs are usually dissipated. See Blanchard (2000) and Kramarz et al. (2004) for details.
} 


\begin{tabular}{cccccc}
\hline \hline & Benchmark & EPL Reform & & Benchmark & EPL Reform \\
\hline$\overline{J C}$ & 5.4672 & 5.4599 & $\sigma_{J C}$ & 0.1753 & 0.1500 \\
$\overline{J D}$ & 5.4668 & 5.4596 & $\sigma_{J D}$ & 0.2145 & 0.1384 \\
$\bar{u}$ & 9.1718 & 9.1549 & $\sigma_{u}$ & 0.3908 & 0.3286 \\
$\bar{Y}$ & 30.9410 & 30.8982 & $\sigma_{Y}$ & 1.2480 & 1.2234 \\
\hline \hline
\end{tabular}

Table 6: Firing costs (red tape and legal costs) as a means of financing the UI system. Simulation Statistics for 100 series of 400 quarters. Mean and standard deviation for the job creation, job destruction, the unemployment rate and production. The data are logged and HP filtered.

0.02 percentage points). While, under this specification, there are no significant reform effects on the means, the cyclical properties of the relevant variables are still affected. In particular, from Table 6 , the reform significantly decreases the variability of unemployment and production. ${ }^{26}$ Thus even without fiscal asymmetry between the two EPL components, the state-contingent layoff tax continues to smooth employment over the business cycle. Finally, note that the reform stabilizes production and slightly decreases its mean. This suggests a possible policy trade-off between employment variability and net production.

At this stage, the dynamic analysis therefore provides evidence in favor of a state-contingent layoff tax compared to a standard EPL package. An EPL reform whose mainstay consists of the introduction of a layoff tax in the place of mandatory firing costs appears to improve labor market performance by encouraging and stabilizing employment, reducing unemployment benefit expenses and increasing production.

\section{Conclusion}

Using an equilibrium unemployment model, we have analyzed the advantages of an employment legislation reform (EPL) which aims to reduce the red tape and legal costs associated with layoffs and introduce a U.S.-like experience-rating system modelled as a combination of a statecontingent layoff tax and a payroll subsidy. The state-contingent layoff tax is remarkable since it is an EPL component with a fiscal counterpart. Our results suggest that EPL efficiency is strongly influenced by the design of such a reform. These results are consistent with the conventional wisdom that experience rating is desirable, not only as a part of unemploymentcompensation finance, as most studies acknowledge, but also as part and parcel of a virtuous EPL system. The EPL reform considered here yields a number of original results: (i) contrary to the red tape and legal costs, the effects of the layoff tax are asymmetric over the business cycle; (ii) the EPL reform improves overall labor market performance, hence alleviating the

\footnotetext{
${ }^{26}$ The results are robust to the specification of the balanced-budget rule. The results are available upon request from the authors
} 
unemployment insurance budget, increasing production and decreasing the unemployment rate, the decrease in the latter being more pronounced the more depressed is the macroeconomic environment; and (iii) the EPL reform reduces the aggregate variability of employment, as the state-contingent layoff tax smoothes the effects of changes in the macroeconomic environment.

More generally, the reform considered shows that it is possible (and desirable) to improve the efficiency of employment protection policies while leaving workers' protection unchanged on the labor market. These results are of particular acuity in the European debate on the contours of employment protection reform, as recently sketched by Blanchard and Tirole (2003a,b) and Cahuc and Kramarz (2005). They suggest that an EPL package adapted from the U.S. experience-rating system is an efficient means of improving labor market performance, while reducing unemployment and stabilizing employment over the business cycle. It may however be legitimate to ask questions about the virtue of experience rating, since this system is notably absent in most OECD countries. In other words, what is the rationale for not implementing this reform? One possible answer pertains to the time schedule of the reform. A short-run oriented government (vote-catching) may be reluctant to support the reform due to the ad hoc losses, and will favor marginal reforms which appear politically less costly. To some extent, this parallels the experience of Europe, and particularly Continental Europe, where the use of experience rating has been advocated since the mid 1990's (OECD, 1994) and where marginal reforms were preferred (Boeri and Garibaldi, 2007).

Our research could be extended in several directions. The results advocated in this paper are complementary to the work of Cahuc and Zylberberg (2007) who argue that in an optimal-taxation framework, "layoff taxes are not only a counterpart to the state provision of unemployment benefits but also a natural counterpart to other public expenditures". In such a context, the introduction of a layoff tax allows unemployment's social cost to be taken into account, where these amount to the unemployment benefits paid to the fired worker plus the fiscal losses to the government when the job is destroyed. From this perspective, an extension that combines a search and matching framework with optimal taxation will further capture the distortions induced by firms' layoff decisions. A second, and perhaps more natural, extension is justified on the grounds that there is no explicit reason for public policies in our model since workers are assumed to be risk neutral. With this assumption we have intentionally focussed on the consequences of the reform on employment and put insurance issues to one side. An extension incorporating both considerations would allow for an explicit welfare evaluation. Finally, in order to fine-tune our understanding of EPL reform (or more generally the introduction of layoff 
taxes), it would be useful to consider a model allowing for worker heterogeneity for at least two reasons: (i) a layoff tax may have redistributive effects across individuals with different abilities; and (ii) a tax might durably exclude workers from the labor market, fostering transitions from unemployment to inactivity. These developments form part of our future research agenda.

\section{References}

[1] Albrecht, J., Vroman, S., (1999), "Unemployment Finance and Efficiency Wages", Journal of Labor Economics, vol. 17, 1, pp. 141-167.

[2] Anderson, P., (1993), "Linear Adjustment Costs and Seasonal Labor Demand: Evidence from Retail Trade Firms", Quarterly Journal of Economics, vol. 108, 4, pp. 1015-1042.

[3] Anderson, P., Meyer, B., (2000), "The Effects of the Unemployment Insurance Payroll Tax on Wages, Employment, Claims and Denials", Journal of Public Economics, vol. 78, pp. 81-106.

[4] Baicker, K., Goldin, C., Katz L., (1997), "A Distinctive System: Origins and Impact of U.S. Unemployment Compensation", NBER Working Paper, 5889.

[5] Bertola, G., (2004), "A Pure Theory of Job Security and Labour Income Risk", Review of Economic Studies, vol. 71, 1, pp. 43-61.

[6] Blanchard, O., (2000), "The Economics of Unemployment: Shocks, Institutions, and Interactions", Lionel Robbins Lectures.

[7] Blanchard, O., Landier, A., (2002), "The Perverse Effects of Partial Labor Market Reform: Fixed Duration Contracts in France", Economic Journal, vol. 112, pp. F214-244.

[8] Blanchard, O., Tirole, J., (2003a), Protection de l'emploi et procédures de licenciement, Rapport pour le Conseil d'Analyse Economique, 44, Paris : La documentation Française.

[9] Blanchard, O., Tirole, J., (2003b), "Contours of Employment Protection Reform", MIT Working Paper 03-35.

[10] Blanchard, O., Tirole, J., (2008), "The Joint Design of Unemployment Insurance and Employment Protection. A First Pass", forthcoming in the Journal of the European Economic Association.

[11] Boeri, T., Garibaldi, P., (2007), "Two Tier Reforms of Employment Protection Legislation. A Honeymoon Effect?", Economic Journal, vol. 117, pp. 357-385.

[12] Boeri, T., Bertola, G., Cazes, S., (2000), "Employment protection in industrialized countries: The case for new indicators", International Labour Review, vol. 139, pp. 1-24.

[13] Burdett, K., Wright, R., (1989), "Optimal Firm Size, Taxes and Unemployment", Journal of Public Economics, vol. 39, pp. 275-287.

[14] Cahuc, P., (2003), "Pour une meilleure protection de l'emploi", Document de travail du COE, 63 . 
[15] Cahuc, P., Kramarz, F., (2005), De la précarité à la mobilité : vers une sécurité sociale professionnelle, Rapport au Ministre d'Etat, Ministre des Finances et de l'Industrie, et au Ministre de l'Emploi du Travail et de la Cohésion Sociale, Paris : La documentation Française.

[16] Cahuc, P., Malherbet, F., (2004), "Unemployment Compensation Finance and Labor Market Rigidity", Journal of Public Economics, vol. 88, pp. 481-501.

[17] Cahuc, P., Postel-Vinay, F., (2002), "Temporary Jobs, Employment Protection and Labor Market Performance", Labour Economics, vol. 9, pp. 63-91.

[18] Cahuc, P., Zylberberg, A., (2007), "Optimal Taxation and Layoff Taxes", forthcoming in the Journal of Public Economics.

[19] Card, D., Levine, P., (1994), "Unemployment Insurance Taxes and the Cyclical and Seasonal Properties of Unemployment", Journal of Public Economics, vol. 53, pp. 1-29.

[20] Cole, H., Rogerson, R., (1999), "Can the Mortensen-Pissarides Matching Model Match the Business Cycle Facts?", International Economic Review, vol. 40, pp. 933-960.

[21] Davis, S., Haltiwanger, J., (1999), "Gross Job Flows", In Handbook of Labor Economics, 3, Edited by O. Ashenfelter and D. Card. Elsevier Science.

[22] Den Haan, W., Ramey, G., Watson, J., (2000), "Job Destruction and Propagation of Shocks", American Economic Review, vol. 90, pp. 482-498.

[23] Duhautois, R., (2002), "Les réallocations d'emplois en France sont-elles en phase avec le cycle ?", Economie et Statistique, vol. 351, pp. 87-103.

[24] E.U. Council, (2003), On guidelines for the employment policies of the member states, available at http://ec.europa.eu/employment_social/employment_strategy.

[25] Fath, J., Fuest, C., (2005), "Experience Rating versus Employment Protection Laws in a Model where Firms Monitor Workers", Scandinavian Journal of Economics, vol. 107, pp. 299-313.

[26] Feldstein, M., (1976), "Temporary Layoffs in the Theory of Unemployment", Journal of Political Economy, vol. 84, pp. 937-957.

[27] Fève, P., Langot, F., (1996), "Unemployment and the Business Cycle in a Small Open Economy, GMM Estimation and Testing with French Data", Journal of Economic Dynamics and Control, vol. 20, pp. 1609-1639.

[28] Garibaldi, P., Violante, G., (2005), "The Employment Effects of Severance Payments With Wage Rigidities", Economic Journal, vol. 115, pp. 799-832.

[29] Gomes, J., Greenwood, J., Rebelo, S., (2001), "Equilibrium Unemployment", Journal of Monetary Economics, vol. 48, pp. 109-152.

[30] Hall, R., Milgrom, P., (2008), "The Limited Influence of Unemployment on the Wage Bargain", forthcoming in theAmerican Economic Review.

[31] Holmlund, B., (1998), "Unemployment Insurance in Theory and Practice", Scandinavian Journal of Economics, vol. 100, pp. 113-141. 
[32] Karamé, F., (2000), Créations, suppressions et réallocations agrégés des emplois en France et aux Etats-Unis : Modélisations et validations économétriques, Thèse de doctorat, Université Paris 1 - Panthéon - Sorbonne.

[33] Kramarz, F., Michaud, M. L., (2004), "The Shape of Hiring and Separation Costs", CEPR Working Paper, 3685.

[34] L'Haridon, O., (2005), "Financement des politiques du marché du travail et protection de l'emploi", Economie et Prévision, 168, pp. 43-62.

[35] Lazear, E., (1990), "Job Security Provisions and Unemployment", Quarterly Journal of Economics, vol. 105, pp. 699-726.

[36] Lindbeck, A., Snower, D., (1988), The Insider-Outsider Theory of Unemployment and Employment, Cambridge: MIT Press.

[37] MacLeod, B., Malcomson, J., (1993). "Investments, Holdup, and the Form of Market Contracts, American Economic Review, vol. 83, pp. 811-37.

[38] Malherbet, F., (2003), Modulation des cotisations patronales à l'assurance chômage, protection de l'emploi et performance du marché du travail, Thèse de doctorat, Université Paris 1 - Panthéon - Sorbonne.

[39] Marceau, N., (1993), "Unemployment Insurance and Market Structure", Journal of Public Economics, vol. 52, pp. 237-249.

[40] Millard, S., Mortensen, D., (1997), "The Unemployment and Welfare Effects of Labour Market Policy: A Comparison of the U.S. and U.K.", In Unemployment Policy: Government Options for the Labour Market, Edited by Dennis J. Snower and Guillermo de la Dehesa. New York: Cambridge University Press.

[41] Mongrain, S., Roberts, J., (2005), "Unemployment Insurance and Experience Rating: Insurance versus Efficiency", International Economic Review, vol. 46, pp. 1303-1320.

[42] Mortensen, D., Pissarides, C., (1994), "Job Creation and Job Destruction in the Theory of Unemployment", Review of Economic Studies, vol. 61, pp. 397-415.

[43] Mortensen, D., Pissarides, C., (1999a), "New Developments in Models of Search in the Labor Market", In Handbook of Labor Economics, 3, Edited by O. Ashenfelter and D.Card. Amsterdam: Elsevier Science.

[44] Mortensen, D., Pissarides, C., (1999b), "Job Reallocation, Employment Fluctuations and Unemployment", In Handbook of Macroeconomics, 1, Edited by J. Taylor and M. Woodford. Amsterdam: Elsevier Science.

[45] Mortensen, D., Nagypal, E., (2007), "More on Unemployment and Vacancy", Review of Economic Dynamics, forthcoming.

[46] OECD, (1999, 2002, 2004, 2005), Employment Outlook, Paris : OCDE.

[47] Petrongolo, B., Pissarides, C., (2001), "Looking into the black box: A survey of the matching function", Journal of Economic Literature, vol. 39, pp. 390-431. 
[48] Pissarides, C., (1994), "Search Unemployment with On-the-Job Search", Review of Economic Studies, vol. 61, pp. 457-475.

[49] Pissarides, C., (2000), Equilibrium Unemployment Theory, Second Edition, Cambridge: MIT Press.

[50] Pissarides, C., (2001), "Employment Protection", Labour Economics, vol. 8, pp. 131-159.

[51] Pissarides, C., (2007), "The Unemployment Volatility Puzzle: Is Wage Stickiness the Answer?", Mimeo CEP-LSE.

[52] Rocheteau, G. (1999), "Balanced-Budget Rules and Indeterminacy of the Equilibrium Unemployment Rate", Oxford Economic Papers, vol. 51, pp 399-409.

[53] Rogerson, R., Shimer, R., Wright, R., (2005), "Search-Theoretic Models of the Labor Market: A Survey", Journal of Economic Literature, vol. 43, pp. 959-988.

[54] Shimer, R., (2005), "The Cyclical Behavior of Equilibrium Unemployment and Vacancies", American Economic Review, vol. 95, pp. 25-49.

[55] UIPL, (1999), Unemployment Insurance Program Letter 05-99 Attachment I, National Association of State WorkForce Agencies, available at http://www.icesa.org.

[56] Yashiv, E., (2006), "Evaluating the Performance of the Search and Matching Model", European Economic Review, vol.50, pp. 909-936.

\section{Appendix}

\section{Appendix 1 - Wage Rules}

\section{Outsiders' Wages (Entrants) — Negotiation -}

Wages are the outcome of a Nash sharing rule providing a share $\gamma \in[0 ; 1]$ of the surplus to the worker. The wage on a new job is given by:

$$
w_{o_{i}}\left(\varepsilon_{u}\right)=\arg \max \left(V_{o_{i}}\left(\varepsilon_{u}\right)-V_{u_{i}}\right)^{\gamma}\left(\Pi_{o_{i}}\left(\varepsilon_{u}\right)-\Pi_{v_{i}}\right)^{1-\gamma}
$$

The bargain yields the following sharing rules:

$$
V_{o_{i}}\left(\varepsilon_{u}\right)-V_{u_{i}}=\gamma S_{o_{i}}\left(\varepsilon_{u}\right) \text { and } \Pi_{o_{i}}\left(\varepsilon_{u}\right)-\Pi_{v_{i}}=(1-\gamma) S_{o_{i}}\left(\varepsilon_{u}\right)
$$

where $S_{o_{i}}\left(\varepsilon_{u}\right)$ denotes the surplus on a new job. Taking account of the free-entry condition, $\Pi_{v_{i}}=0$, we simply obtain:

$$
(1-\gamma)\left[V_{o_{i}}\left(\varepsilon_{u}\right)-V_{u_{i}}\right]=\gamma \Pi_{o_{i}}\left(\varepsilon_{u}\right)
$$

Using equations (2) and (5), presented in the text, we have:

$$
\begin{gathered}
\left(\rho+\lambda+\sum_{i \neq j}^{n} \Omega_{i j}\right) \Pi_{o_{i}}\left(\varepsilon_{u}\right)=p_{i}+\sigma \varepsilon_{u}-\tau_{i}-w_{o_{i}}\left(\varepsilon_{u}\right) \\
+\lambda\left[\int \operatorname{Max}\left[\Pi_{e_{i}}(\zeta)+f+\tau_{e_{i}}, 0\right] d G(\zeta)\right]+\sum_{i \neq j}^{n} \Omega_{i j}\left[\Pi_{o_{j}}\left(\varepsilon_{u}\right)\right]-\lambda\left(f+\tau_{e_{i}}\right),
\end{gathered}
$$




$$
\begin{array}{r}
\left(\rho+\lambda+\sum_{i \neq j}^{n} \Omega_{i j}\right)\left(V_{o_{i}}\left(\varepsilon_{u}\right)\right. \\
\left.-V_{u_{i}}\right)=w_{o_{i}}\left(\varepsilon_{u}\right)+\lambda\left[\int \operatorname{Max}\left[V_{e_{i}}(\zeta)-V_{u_{i}}, 0\right] d G(\zeta)\right] \\
+\sum_{i \neq j}^{n} \Omega_{i j}\left[V_{o_{j}}\left(\varepsilon_{u}\right)-V_{u_{j}}\right]-\rho V_{u_{i}}-\sum_{i \neq j}^{n} \Omega_{i j}\left(V_{u_{i}}-V_{u_{j}}\right) .
\end{array}
$$

Again, using the sharing rules as well as the free-entry condition, the expected utility of an unemployed worker is:

$$
\rho V_{u_{i}}+\sum_{i \neq j}^{n} \Omega_{i j}\left(V_{u_{i}}-V_{u_{j}}\right)=b+\theta_{i} \frac{\gamma}{1-\gamma} h .
$$

Hence, using the previous expressions with the sharing rules, the outsiders' wage is given by (11).

\section{Insiders' Wages (Incumbents) — Renegotiation -}

The wage on a continuing job is given by:

$$
w_{i}(\varepsilon)=\arg \max \left(V_{e_{i}}(\varepsilon)-V_{u_{i}}\right)^{\gamma}\left(\Pi_{e_{i}}(\varepsilon)-\Pi_{v_{i}}+f+\tau_{e_{i}}\right)^{1-\gamma}
$$

The bargain yields the following sharing rules:

$$
V_{e_{i}}(\varepsilon)-V_{u_{i}}=\gamma S_{e_{i}}(\varepsilon) \quad \text { and } \quad \Pi_{e_{i}}(\varepsilon)-\Pi_{v_{i}}+f+\tau_{e_{i}}=(1-\gamma) S_{e_{i}}(\varepsilon)
$$

where $S_{e_{i}}(\varepsilon)$ denotes the surplus on a continuing job. Taking account of the free-entry condition, $\Pi_{v_{i}}=0$, we simply obtain:

$$
(1-\gamma)\left(V_{e_{i}}(\varepsilon)-V_{u_{i}}\right)=\gamma\left(\Pi_{e_{i}}(\varepsilon)+f+\tau_{e_{i}}\right)
$$

Using equations (3) and (6), detailed in the text, we have:

$$
\begin{gathered}
\left(\rho+\lambda+\sum_{i \neq j}^{n} \Omega_{i j}\right)\left(\Pi_{e_{i}}(\varepsilon)+f+\tau_{e_{i}}\right)=p_{i}+\sigma \varepsilon-\tau_{i}-w_{i}(\varepsilon)+\lambda\left[\int \operatorname{Max}\left[\Pi_{e_{i}}(\zeta)+f+\tau_{e_{i}}, 0\right] d G(\zeta)\right] \\
+\sum_{i \neq j}^{n} \Omega_{i j}\left[\operatorname{Max}\left[\Pi_{e_{j}}(\varepsilon)+f+\tau_{e_{j}}, 0\right]\right]+\rho\left(f+\tau_{e_{i}}\right)+\sum_{i \neq j}^{n} \Omega_{i j}\left(\tau_{e_{i}}-\tau_{e_{j}}\right) \\
\left(\begin{array}{c}
\left.\rho+\lambda+\sum_{i \neq j}^{n} \Omega_{i j}\right)\left(V_{e_{i}}(\varepsilon)-V_{u_{i}}\right)=w_{i}(\varepsilon)+\lambda\left[\int \operatorname{Max}\left[V_{e_{i}}(\zeta)-V_{u_{i}}, 0\right] d G(\zeta)\right] \\
+\sum_{i \neq j}^{n} \Omega_{i j}\left[\operatorname{Max}\left[V_{e_{j}}(\varepsilon)-V_{u_{j}}, 0\right]\right]-\rho V_{u_{i}}-\sum_{i \neq j}^{n} \Omega_{i j}\left(V_{u_{i}}-V_{u_{j}}\right)
\end{array}\right.
\end{gathered}
$$

Hence, using the previous equations together with the sharing rules and the expected utility of an unemployed worker, the insider's wage is given by (12). 


\section{Appendix 2 - Surplus, Job Destruction and Job Creation}

\section{Surplus on a New Job}

The surplus on a new job is defined by (7). Using equations (2) and (5) detailed in the text together with the free-entry condition, $\Pi_{v_{i}}=0$, we have:

$$
\begin{aligned}
\left(\rho+\lambda+\sum_{i \neq j}^{n} \Omega_{i j}\right) S_{o_{i}}\left(\varepsilon_{u}\right) & =p_{i}+\sigma \varepsilon_{u}-\tau_{i}-\lambda\left(f+\tau_{e_{i}}\right)-\rho V_{u_{i}} \\
& +\lambda E\left(S_{e_{i}}\right)+\sum_{i \neq j}^{n} \Omega_{i j}\left(V_{u_{j}}-V_{u_{i}}\right)+\sum_{i \neq j}^{n} \Omega_{i j} S_{o_{j}}\left(\varepsilon_{u}\right) .
\end{aligned}
$$

Then, using the sharing rules detailed above together with (1), (4) and the free-entry condition, the surplus on a new job in state $i$ is given by:

$$
\left(\rho+\lambda+\sum_{i \neq j}^{n} \Omega_{i j}\right) S_{o_{i}}\left(\varepsilon_{u}\right)=p_{i}+\sigma \varepsilon_{u}-\tau_{i}-b-\frac{\theta_{i} \gamma h}{1-\gamma}-\lambda\left(f+\tau_{e_{i}}\right)+\lambda E\left(S_{e_{i}}\right)+\sum_{i \neq j}^{n} \Omega_{i j} S_{o_{j}}\left(\varepsilon_{u}\right) .
$$

\section{Surplus on a Continuing Job}

The surplus on a continuing job is defined by (8). Using equations (3) and (6) detailed in the text together with the free-entry condition, $\Pi_{v_{i}}=0$, we obtain:

$$
\begin{array}{r}
\left(\rho+\lambda+\sum_{i \neq j}^{n} \Omega_{i j}\right) S_{e_{i}}(\varepsilon)=p_{i}+\sigma \varepsilon-\tau_{i}-\left(\rho+\sum_{i \neq j}^{n} \Omega_{i j}\right)\left(V_{u_{i}}-f-\tau_{e_{i}}\right) \\
+\sum_{i \neq j}^{n} \Omega_{i j}\left(V_{u_{j}}-f-\tau_{e_{j}}\right)+\lambda E\left(S_{e_{i}}\right)+\sum_{i \neq j}^{n} \Omega_{i j} \operatorname{Max}\left[S_{e_{j}}(\varepsilon), 0\right] .
\end{array}
$$

Finally, using the sharing rules detailed above together with (1), (4) and the free-entry condition, the surplus on a continuing job in state $i$ is given by:

$$
\begin{aligned}
\left(\rho+\lambda+\sum_{i \neq j}^{n} \Omega_{i j}\right) S_{e_{i}}(\varepsilon) & =p_{i}+\sigma \varepsilon-\tau_{i}-b-\theta_{i} \frac{\gamma}{1-\gamma} h+\rho\left(f+\tau_{e_{i}}\right)+\lambda E\left(S_{e_{i}}\right) \\
& +\sum_{i \neq j}^{n} \Omega_{i j}\left(\tau_{e_{i}}-\tau_{e_{j}}\right)+\sum_{i \neq j}^{n} \Omega_{i j}\left[\operatorname{Max}\left[S_{e_{j}}(\varepsilon), 0\right]\right] .
\end{aligned}
$$

\section{Job Destruction}

Combining the formal condition for severance (9) with (A-13), it is easy after some algebra to obtain (13), i.e. the relation defining the job destruction threshold - cutoff productivity - in state $i$. 


\section{Job Creation}

Combining the sharing rules together with (1) and the free-entry condition, it is straightforward to obtain $\frac{h}{q\left(\theta_{i}\right)}=(1-\gamma) S_{o_{i}}\left(\varepsilon_{u}\right)$. Then using this latter expression together with (A-11), after some algebra we obtain (14), that is the relation defining job creation - labor-market tightnessin state $i$.

\section{Appendix 3 - Laws of Motion}

Time is divided into discrete periods indexed by the subscript $t$, where $t=0,1, \ldots, T$ represents a quarterly sequence. Let $N_{t}, C_{t}, D_{t}$ and $Y_{t}$ denote employment at the beginning of period $t$, job creation flows, job destruction flows and aggregate production at time $t$ respectively. The aggregate law of motion for employment is:

$$
N_{t+1}=N_{t}+C_{t}-D_{t}
$$

We now turn to the equations describing the law of motion for employment for each idiosyncratic component of productivity $\varepsilon$. We assume that the aggregate conditions change at the beginning of the time period. It follows that once the macroeconomic environment is revealed, the only remaining source of job destruction is idiosyncratic. Let $n_{t}(\varepsilon)$ and $n_{t+1}(\varepsilon)$ represent the number of workers whose productivity on the job is $\varepsilon$ in $t$ and $t+1$ respectively. The number of workers whose productivity is $\varepsilon$ at the beginning of period $t+1$ is given by:

$$
n_{t+1}(\varepsilon)=\left\{\begin{array}{cl}
(1-\lambda) n_{t}(\varepsilon)+\lambda G^{\prime}(\varepsilon)\left[N_{t}-\int_{\varepsilon_{l}}^{\varepsilon_{d i t}} n_{t}(\zeta) d \zeta\right] & \text { if } \varepsilon_{u}>\varepsilon \geq \varepsilon_{d_{i t}} \\
0 & \text { if } \varepsilon<\varepsilon_{d_{i t}}
\end{array}\right.
$$

where $\varepsilon_{d_{i t}}$ is the reservation productivity contingent on the current aggregate state $i$ and for the time period $t$. The dynamic law of motion for employment is given by the first line of equation (A-15) provided the idiosyncratic component is in the range $\left[\varepsilon_{d_{i t}}, \varepsilon_{u}\right.$ [ and by the second term for all other values. The first term of (A-15) denotes the mass of jobs that has not been hit by an idiosyncratic productivity shock whereas the second term refers to the mass of surviving jobs with job-specific component equal to $\varepsilon$ that has been hit by an idiosyncratic productivity shock. The job creation flow in period $t$ is:

$$
C_{t}=\theta_{i t} q\left(\theta_{i t}\right)\left(1-N_{t}\right)
$$

where $\theta_{i t} q\left(\theta_{i t}\right)$ is the job-finding rate. Jobs are destroyed for one of two reasons. First, aggregate conditions may worsen and cause the productivity threshold to be shifted up. As a consequence, all jobs whose productivity is below the new cut-off value are destroyed. Second, idiosyncratic productivity may change at Poisson rate $\lambda$ and cause the job-specific component to fall below the existing cut-off value. The job destruction flow is given by:

$$
D_{t}=\int_{\varepsilon_{l}}^{\varepsilon_{d_{i t}}} n_{t}(\zeta) d \zeta+\lambda G\left(\varepsilon_{d_{i t}}\right)\left[N_{t}-\int_{\varepsilon_{l}}^{\varepsilon_{d_{i t}}} n_{t}(\zeta) d \zeta\right] .
$$


The laws of motion for unemployment, $U_{t}$, for new jobs, $n_{h}$, and for continuing jobs, $n_{c}$, are respectively:

$$
\begin{gathered}
U_{t}=1-N_{t} \\
n_{h_{t+1}}=C_{t}+(1-\lambda) n_{h_{t}} \\
n_{c_{t+1}}=n_{c_{t}}+\lambda\left[1-G\left(\varepsilon_{d_{i t}}\right)\right] n_{h_{t}}-D_{t}
\end{gathered}
$$

Finally, gross aggregate production, $Y_{t}$, is the sum of the productivity of new and continuing jobs:

$$
Y_{t}=n_{h_{t}}\left(p_{i t}+\sigma \varepsilon_{u}\right)+n_{c_{t}} \int_{\varepsilon_{d_{i t}}}^{\varepsilon_{u}}\left(p_{i t}+\sigma \zeta\right) \frac{d G(\zeta)}{1-G\left(\varepsilon_{d_{i t}}\right)}
$$

It follows that net aggregate production is worth:

$$
Y_{t}^{n e t}=n_{h_{t}}\left(p_{i t}+\sigma \varepsilon_{u}\right)+n_{c_{t}} \int_{\varepsilon_{d_{i t}}}^{\varepsilon_{u}}\left(p_{i t}+\sigma \zeta\right) \frac{d G(\zeta)}{1-G\left(\varepsilon_{d_{i t}}\right)}-\theta_{i t} U_{t} h-\Xi D_{t} f
$$

where $\Xi$ is a dummy variable which equals 0 if firing costs, $f$, are real resource costs, and 1 otherwise. 